\title{
Observations of nonlinear momentum fluxes over the inner continental shelf
}

\author{
Thomas P. Connolly ${ }^{1}$ and Steven J. Lentz ${ }^{2}$ \\ ${ }^{1}$ Moss Landing Marine Laboratories \\ San José State University \\ 8272 Moss Landing Rd., Moss Landing, CA, 95039 \\ tconnolly@mlml.calstate.edu (corresponding author) \\ ${ }^{2}$ Woods Hole Oceanographic Institution \\ 266 Woods Hole Road, MS 21, Woods Hole, MA, 02543 \\ slentz@whoi.edu
}

June 21,2021

This is a preprint of a peer-reviewed manuscript which has been accepted for publication at the Journal of Marine Research. When available, a link to the published version of this manuscript will be available via the "Peer-reviewed Publication DOI" link on EarthArXiv.

Preprint DOI: https://doi.org/10.31223/X5531C 
2 Nonlinear momentum fluxes over the inner continental shelf are examined using moored observations from multiple years at two different locations in the Middle Atlantic Bight.

4 Inner shelf dynamics are often described in terms of a linear alongshore momentum bal5 ance, dominated by frictional stresses generated at the surface and bottom. In this study, 6 observations over the North Carolina inner shelf show that the divergence of the cross7 shelf flux of alongshore momentum is often substantial relative to the wind stress during 8 periods of strong stratification. During upwelling at this location, offshore fluxes of along9 shore momentum in the surface layer partially balance the wind stress and reduce the role 10 of the bottom stress. During downwelling, onshore fluxes of alongshore momentum re11 inforce the wind stress and increase the role of bottom stress. Over the New England 12 inner shelf, nonlinear terms have less of an impact in the momentum balance and exhibit

different relationships with the wind forcing. Differences between locations and time periods are explained by variations in bottom slope, latitude, vertical shear and cross-shelf exchange. Over the New England inner shelf, where moored density data are available, variations in vertical shear are explained by a combination of thermal wind balance and wind stress. An implication of this study is that cross-shelf winds can potentially influence the alongshore momentum balance over the inner shelf, in contrast with deeper locations over the middle to outer shelf.

Keywords - Momentum balance, Nonlinear, Momentum flux, Coastal dynamics, Upwelling dynamics, Downwelling dynamics, Thermal wind balance, Inner shelf 


\section{Introduction}

The dynamics of the inner continental shelf govern exchange between shallower wa-

ters in the surf zone and deeper waters over the middle to outer shelf. The inner shelf is often dynamically defined as a region where the surface and bottom boundary layers interact and turbulent stresses are present throughout the entire water column (Mitchum and Clarke, 1986; Lentz, 1995; Lentz and Fewings, 2012). The inner shelf region is also characterized by cross-shelf mass transport that is reduced from the theoretical Ekman transport expected for deeper water (Lentz et al., 1999; Kirincich et al., 2005). The offshore extent of the inner shelf is strongly influenced by stratification, which inhibits turbulent mixing and restricts the region of reduced cross-shelf transport to shallower depths (Lentz et al., 1999). Unlike the middle to outer shelf, cross-shelf winds often drive significant transport and influence turbulent mixing over the inner shelf (Tilburg, 2003; Fewings et al., 2008; Horwitz and Lentz, 2014). In the unique dynamical regime of the inner shelf, cross-shelf exchange is part of a complex set of interactions between wind forcing, stratification, density fronts and boundary-layer turbulence.

The alongshore momentum balance is frequently used as a framework for understanding the dynamics of coastal regions, including the inner shelf. The depth-averaged balance over the inner shelf is often characterized as being dominated by the frictional terms, wind stress and bottom stress, with secondary contributions from local acceleration and alongshore pressure gradients (Hickey, 1989; Lentz et al., 1999; Lentz and Fewings, 2012). The alongshore pressure gradient has also been shown to be important in balancing the wind stress at some locations, particularly at locations near alongshore variations in bathymetry and coastline (Kirincich and Barth, 2009b; Fewings and Lentz, 2010). However, the potential impact of additional nonlinear terms in the alongshore momentum balance is not well known and is often neglected for simplicity (Lentz and Fewings, 2012). If nonlinear terms are significant, neglecting them could lead to misinterpretation of the magnitude of stresses at the bottom or in the interior of the water column, which are often uncertain 
or unknown. The goal of this study is to assess the importance of nonlinear momentum fluxes in observations at different locations, and provide a mechanistic understanding of how they arise in response to wind forcing over the inner shelf.

In deeper water over the middle to outer shelf, nonlinear momentum fluxes have been found to strongly influence upwelling dynamics under certain conditions. Lentz and Chapman (2004) show that the divergence of the cross-shelf flux of alongshore momentum is important in balancing upwelling-favorable alongshore wind stress over continental shelves characterized by strong stratification and a steep bottom slope. At locations with strong stratification and steep bottom slope, the role of bottom friction is reduced and the onshore return flow occurs in the geostrophic interior region between the turbulent boundary layers, rather than in the bottom boundary layer. Theory also predicts that cross-shelf momentum flux divergence reinforces the wind stress during downwellingfavorable wind forcing, allowing the magnitude of the bottom stress to exceed that of the wind stress (Lentz and Chapman, 2004). The role of the nonlinear momentum flux divergence is unclear over the inner shelf where the boundary layers interact, there is no distinct geostrophic interior region and cross-shore wind stress can be an important part of the forcing.

Previous studies that have taken nonlinear terms into account over the inner shelf have focused on a range of different mechanisms and have reached different conclusions about the importance of nonlinear processes. In Monterey Bay on the central California coast, Woodson (2013) found that nonlinear interaction between offshore surface transport and relative vorticity associated with the alongshore flow can be important in balancing wind stress in the surface layer, along with the Coriolis force. These observations, combined with high levels of stratification and shallow estimates of the boundary layer thickness, suggest that the reduction of surface transport from theoretical Ekman transport is not necessarily associated with significant stress at the base of the surface layer. Over the Oregon inner shelf, Kirincich and Barth (2009b) found the divergence of the cross-shelf flux 
of along-shelf momentum to be important in balancing the wind stress. The presence of strong vertical shear in these observations indicates that the mechanism is similar to that described by Lentz and Chapman (2004) for mid-shelf locations, although the importance of the nonlinear term over the Oregon inner shelf varies at different sites along the same isobath with similar stratification and bottom slope. Estimates of this nonlinear term are also substantial relative to the wind stress during periods of strong stratification over the Catalan inner shelf in the Mediterranean (Grifoll et al., 2012). However, numerical modeling over the West Florida shelf indicates that the nonlinear terms are small, consistent with a linear balance (Liu and Weisberg, 2005). Observations from a range of different locations, and subject to a range of different forcing conditions, are needed to clarify the role of this nonlinear process over the inner shelf.

This study assesses the role of nonlinear momentum fluxes in the alongshore momentum balance at two different inner shelf locations in the Middle Atlantic Bight: the Martha's Vineyard Coastal Observatory (MVCO) over the New England inner shelf and the Army Corps of Engineers Field Research Facility (FRF) over the North Carolina inner shelf (Fig. 1). Because of differences in latitude and coastline orientation, these two locations are subject to different seasonal variations in wind forcing, but a strong cross-shelf component of wind stress is present at both locations (Lentz, 2008a). Tidal height amplitudes at the dominant M2 frequency are between $0.4-0.5 \mathrm{~m}$ at each site, but tidal current amplitudes increase substantially from $<0.1 \mathrm{~m} / \mathrm{s}$ near FRF from $\sim 0.3 \mathrm{~m} / \mathrm{s}$ near MVCO (Moody et al., 1984). At MVCO, the alongshore momentum balance has primarily been examined in a linearized framework, and a dominant balance between the wind stress and alongshore pressure gradient has been observed (Fewings and Lentz, 2010). At FRF, Lentz et al. (1999) also examined a linearized momentum balance and identified a dominant balance between the wind stress and bottom stress. Nonlinear terms have also been neglected in the alongshore momentum balance integrated over the surface layer at this site (Lentz, 2001). However, numerical modeling suggests that nonlinear momentum fluxes strongly 
influence the alongshore momentum balance at FRF, playing a major role in balancing the wind stress during upwelling and a more minor role in reinforcing the wind stress during downwelling (Kuebel Cervantes et al., 2003; 2004). In the present study, observations from both sites are compared under a range of forcing conditions to assess the importance of the nonlinear terms and identify physical mechanisms that determine how and when they become important.

At each location, data from long-term current meter arrays are used to evaluate the importance of the nonlinear terms in alongshore momentum balances. In Section 2, alongshore momentum balance equations are presented in two forms, both depth-averaged and integrated over the surface layer. Observations and methods for estimating terms of the momentum balance are presented in Section 3. Descriptive overviews of the MVCO and FRF observations are provided (Section 4.a), before presenting analyses of the depthaveraged and surface-integrated momentum balances (Sections 4.b,c). Processes influencing vertical shear, an important component of the nonlinear momentum flux divergence, are evaluated using moored density time series observations at MVCO (Section 4.d). As discussed in Section 5, it is found that the contrasting patterns of wind forcing and crossshelf exchange at MVCO and FRF lead to different relationships between the alongshore wind stress and the momentum flux divergence. These differences can be explained by a combination of bottom slope, vertical shear, the Coriolis parameter, and the fraction of cross-shelf surface transport relative to the deep water Ekman transport.

\section{Alongshore momentum balances}

To provide a theoretical framework for the analysis, simplified alongshore momentum balances are developed for the inner continental shelf. The primary purpose of the momentum balance analysis is to assess the importance of the cross-shelf momentum flux divergence. A major simplification is the assumption of a two-dimensional mass balance, neglecting alongshore variations in currents and the surface gravity wave field. There is 
evidence for this type of mass balance at both inner-shelf locations examined in this study when the effects of wave-driven transport are included (Lentz et al., 2008). However, this assumption would not be valid in locations where alongshore variations in topography are present over short scales and alongshore advection of momentum can be important in balancing localized pressure gradients (e.g. Ofsthun et al., 2019). The effects of wave breaking in the surf zone are also not included in the analysis, which focuses on the inner shelf region offshore of the surf zone.

The effects of unbroken surface gravity waves over the inner shelf are accounted for by considering the wave-averaged Lagrangian cross-shelf velocity $\mathbf{u}_{L}=\mathbf{u}+\mathbf{u}_{s t}$, where $\mathbf{u}$ is the wave-averaged Eulerian velocity vector and $\mathbf{u}_{s t}$ is the Stokes drift vector. Waveaveraged observations collected by a current meter at a fixed location represent only the Eulerian component $\mathbf{u}$, but $\mathbf{u}_{s t}$ also contributes to additional transport of mass and tracers in the direction of wave propagation (Monismith and Fong, 2004). The presence of the Stokes drift, $\mathbf{u}_{s t}$, influences the alongshore momentum balance through the StokesCoriolis force (Xu and Bowen, 1994; Lentz et al., 2008) and vortex force terms (Smith, 2006; Uchiyama et al., 2010).

\section{a. Depth-averaged momentum balance}

As a starting point for developing a simplified two-dimensional momentum balance for the inner shelf, a three-dimensional balance that includes the effects of wave breaking is first considered. The $x$ coordinate is defined as positive offshore, and the $y$ coordinate is oriented alongshore (Fig. 1b,c). Following Uchiyama et al. (2010), a depth-averaged alongshore momentum balance that includes the effects of both breaking and unbroken surface waves can be written in a flux-divergence form, 


$$
\begin{array}{r}
\frac{\partial \bar{v}}{\partial t}+\frac{1}{D} \frac{\partial}{\partial x} \int_{-h}^{\eta}\left(u_{L} v\right) d z+\frac{1}{D} \frac{\partial}{\partial y} \int_{-h}^{\eta}\left(v_{L} v\right) d z-\left(\overline{u_{s t} \frac{\partial u}{\partial y}}\right)-\left(\overline{v_{s t} \frac{\partial v}{\partial y}}\right) \\
=-\frac{1}{\rho_{o}} \frac{\partial \bar{p}}{\partial y}-f \bar{u}_{L}+\frac{\tau^{s y}}{\rho_{o} D}-\frac{\tau^{b y}}{\rho_{o} D}+\frac{\epsilon k^{y}}{\rho_{o} D \sigma}
\end{array}
$$

where $\eta$ is sea level, $h$ is bottom depth, $D=\eta+h$ is the total thickness of the water column, $\rho_{o}=1025 \mathrm{~kg} / \mathrm{m}^{3}$ is a constant reference density, $f$ is the Coriolis parameter, $\tau^{s y}$ is the alongshore component of surface wind stress, $\tau^{b y}$ is the alongshore component of bottom stress, $\epsilon$ is the wave dissipation rate, $k^{y}$ is the alongshore component of the wavenumber, and $\sigma$ is the wave frequency. Overbars indicate depth-averaged quantities, for example,

$$
\bar{v}=\frac{1}{D} \int_{-h}^{\eta} v d z
$$

Assuming a two-dimensional mass balance $\left(\bar{u}_{L}=0\right)$, neglecting the effects of wave dissipation outside of the surf zone, and neglecting alongshore variations in currents and waves, the alongshore momentum balance in equation (1) can be simplified as

$$
\frac{\partial \bar{v}}{\partial t}+\frac{1}{D} \frac{\partial}{\partial x} \int_{-h}^{\eta}\left(u_{L} v\right) d z=-\frac{1}{\rho_{o}} \frac{\partial \bar{p}}{\partial y}+\frac{\tau^{s y}}{\rho_{o} D}-\frac{\tau^{b y}}{\rho_{o} D}
$$

The left-hand side of equation (3) includes local acceleration and the nonlinear momentum flux divergence term. This nonlinear term could be decomposed into 1) nonlinear advection of alongshore momentum by the cross-shore Eulerian circulation and 2) the vortex force induced by the interaction of the cross-shelf component of Stokes drift and the alongshore current,

$$
\frac{\partial}{\partial x} \int_{-h}^{\eta}\left(u_{L} v\right) d z=\frac{\partial}{\partial x} \int_{-h}^{\eta}(u v) d z+\frac{\partial}{\partial x} \int_{-h}^{\eta}\left(u_{s t} v\right) d z
$$

Including transport due to Stokes drift is important because it often exceeds the wind- 
driven transport in the surface layer at locations inshore of the 20-m isobath at MVCO and FRF (Lentz et al., 2008). Over the Martha's Vineyard inner shelf, 15-30\% of the crossshelf heat flux during summer is associated with Stokes drift (Fewings and Lentz, 2011). However, Stokes drift is only one component of the wave-driven circulation. The StokesCoriolis force induces an Eulerian wave-driven flow which tends to cancel the Stokes drift in the limit of weak eddy viscosity (Xu and Bowen, 1994; Lentz et al., 2008). To assess the net impact of Stokes drift and Eulerian advection, these two components are combined into a single nonlinear momentum flux divergence term. This term is potentially significant if there is net cross-shelf exchange due to wind and waves $\left(u_{L} \neq 0\right)$, vertical shear in the alongshore current is present $(\partial v / \partial z \neq 0)$, and cross-shelf variations exist $(\partial / \partial x \neq 0)$. This nonlinear term is present in a simplified two-dimensional framework, but it is not present in one-dimensional models of the water column.

The present study primarily uses information from cross-shelf current meter arrays deployed over multiple years at two different inner shelf locations. Although data are not available to accurately estimate the alongshore pressure gradient term, the current meter data allow for estimates of the nonlinear term. Estimates of the nonlinear term are compared with estimates of surface and bottom stresses, and the importance of the nonlinear term is assessed under different wind forcing and stratification conditions.

\section{b. Surface layer momentum balance}

The alongshore momentum balance is also analyzed over a portion of the water column near the surface in order to relate the nonlinear dynamics to cross-shelf exchange and turbulent stresses. Cross-shore surface transport $U_{S}$ is calculated from the vertical integral of the Lagrangian cross-shelf velocity in the upper layer of the water column

$$
U_{S}=\int_{z_{s}}^{\eta} u_{L} d z
$$


where $z_{s}$ is the depth of the first zero crossing in the vertical profile of $u_{L}$. The terms in the alongshore momentum balance are integrated over this same surface layer.

Consistent with the depth-averaged balance described above in Section 2.a, the surface layer momentum balance considered in this study neglects alongshore variations in currents and waves, as well as wave dissipation in the surf zone. The alongshore momentum balance integrated over the upper layer is given by

$$
\frac{\partial}{\partial t} \int_{z_{s}}^{\eta} v d z+\frac{\partial}{\partial x} \int_{z_{s}}^{\eta}\left(u_{L} v\right) d z-\left.\left(w_{L} v\right)\right|_{z=z_{s}}=-\frac{1}{\rho_{o}} \int_{z_{s}}^{\eta} \frac{\partial p}{\partial y} d z-f U_{s}+\frac{\tau^{s y}}{\rho_{o}}-\left.\frac{\tau^{i y}}{\rho_{o}}\right|_{z=z_{s}}
$$

where $w_{L}$ is the Lagrangian vertical velocity and $\left.\tau^{i y}\right|_{z=z_{s}}$ is the interior turbulent stress at the base of the surface layer. The Lagrangian vertical velocity at the base of the surface layer can be determined from conservation of volume,

$$
\left.w_{L}\right|_{z=z_{s}}=\frac{\partial \eta}{\partial t}+\frac{\partial U_{s}}{\partial x} .
$$

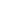

19.$$
1 \text { line }
$$

linear terms. The two nonlinear terms represent the net flux of alongshore momentum into the surface layer at a given cross-shelf location. Both the cross-shore and vertical components of the Lagrangian velocity $\mathbf{u}_{L}$ contribute to the flux of alongshore momentum into the surface layer. Both of these terms are dependent on cross-shore variations $(\partial / \partial x)$ and cannot exist in one-dimensional models of the water column, even those with sophisticated turbulence closure schemes. Although direct observations of interior stresses are not available in this study, implications of the results for turbulent stresses over the inner shelf will be discussed. 


\section{Methods}

\section{a. Data sources}

To address the role of nonlinear terms in the momentum balance, this study uses observations from Duck, NC, and Martha's Vineyard, MA (Fig. 1). At both of these sites, velocity data are available for several years at multiple cross-shelf locations.

i. Duck, NC A long-term array of five acoustic current profilers at bottom depths of 5-11 m, was maintained by the Army Corps of Engineers Field Research Facility (FRF) at Duck, North Carolina (Fig. 1b). Velocity data from the time period November 2008 to July 2014 are used in this study. These data are publicly available on the FRF data portal. At the 5, 6, 8 and 11m sites, Nortek Acoustic Wave and Current (AWAC) profilers obtain velocity profiles with vertical resolution of $0.5 \mathrm{~m}$. The bottom velocity bins are located $1.5 \mathrm{~m}$ above the bottom at the 5 and $6 \mathrm{~m}$ sites and $1.0 \mathrm{~m}$ above the bottom at the 8 and $11 \mathrm{~m}$ sites. Data from bins within $2 \mathrm{~m}$ of the mean sea surface are not included in the analysis. The AWAC profilers also obtain measurements of surface gravity wave characteristics, including significant wave height $\left(H_{\text {sig }}\right)$, peak period and direction.

Stokes drift profiles, $\mathbf{u}_{s t}$, and depth averages, $\overline{\mathbf{u}}_{s t}$, are computed from observed bulk wave characteristics ( $H_{s i g}$, peak period, direction) following Lentz et al. (2008). Time periods when sites are in the surf zone are excluded from the analysis based on a conservative criterion of $H_{\text {sig }}<0.33 h$. When wave data are not available at a site, wave height and period from the nearest available site are used and direction is calculated from the nearest available site using Snell's law. Remaining short gaps of up to 6 hours in $\mathbf{u}_{s t}$ and $\overline{\mathbf{u}}_{s t}$ are filled using linear interpolation. Gaps of the same size in the FRF ADCP velocities are filled by first removing tidal velocities, linearly interpolating over the gaps, then adding back the tidal velocities. The tidal analysis is performed using a Python distribution of UTide (Codiga, 2011), using tidal constituents with periods of less than 48 hours. At each site, all current and Stokes drift vectors are rotated so that the $y$ axis is aligned with principal axis of $\overline{\mathbf{u}}_{L}$. The principal axis angles vary between $18.4-21.6^{\circ}$ counter-clockwise from 
true north.

In addition to the long-term current meter array, conductivity, temperature and depth (CTD) profiles are collected on a nominal daily basis from the end of a pier at FRF (Fig. 1b). These data are used to provide information on water column stratification. Profiles of water column temperature and practical salinity are available through the FRF data portal. Wind speed and direction at the FRF site are measured by an anemometer at a height of $16.4 \mathrm{~m}$ above the water at the end of the FRF pier (NDBC station DUKN7). Wind vectors at FRF are rotated into a coordinate system in which the $y$ axis is $20^{\circ}$ counter-clockwise from true north.

Nearshore bathymetry data (Fig. 1b) near Duck, NC were collected by Dr. Jesse McNinch and are available in Thieler et al. (2013). Nearshore bathymetry data used for depths 2.5-9 $\mathrm{m}$ are gridded at 10-m horizontal resolution; data used for depths 10 $\mathrm{m}$ and greater are gridded at 40-m horizontal resolution. Regional-scale bathymetry data on a 30 arc-second grid were obtained from the General Bathymetric Chart of the Oceans GEBCO_2014 Grid, version 20150318 (http://www.gebco.net, Fig. 1a).

ii. Martha's Vineyard, MA As part of the Stratification, Wind, and Waves on the Inner shelf of Martha's Vineyard (SWWIM) field program, an array of moorings was deployed during the time period from October 2006 to February 2010. The cross-shelf array consisted of four sites ranging in depth from $7 \mathrm{~m}$ to $27 \mathrm{~m}$. A description of the complete data set is given by Horwitz and Lentz (2016), and a brief summary of the relevant data is provided here.

To facilitate comparison with the data from FRF, where the deepest site is at $11 \mathrm{~m}$, this study focuses on the two inshore SWWIM sites at $7 \mathrm{~m}$ and $12 \mathrm{~m}$ (Fig. 1c). Velocity data from the 7-m site were obtained from an upward-looking $1200 \mathrm{kHz}$ ADCP. Vertical bins used for analysis span heights from $1.75 \mathrm{~m}$ above the bottom to within $0.75 \mathrm{~m}$ from the surface, with $0.25 \mathrm{~m}$ vertical spacing. Data were collected at $1 \mathrm{~Hz}$ in $6.7 \mathrm{~min}$ or $9 \mathrm{~min}$ bursts and averaged every $20 \mathrm{~min}$. At the 12-m site, a 1200-kHz ADCP collected data at a 
cabled node of the MVCO. Vertical bins used for analysis span heights from $2.5 \mathrm{~m}$ above the bottom to within $2.5 \mathrm{~m}$ below the surface, with $0.5 \mathrm{~m}$ vertical spacing. Data were collected at $2 \mathrm{~Hz}$ and averaged into 20 min ensembles. The ADCP data at the 12-m site are also used to compute wave characteristics, including $H_{\text {sig }}$, peak period and direction.

Stokes drift is calculated in the same manner as the FRF data. In the SWWIM data, where tidal velocities account for a greater fraction of the variance, a more restrictive threshold of 1 hour is used for linear interpolation of gaps. Principal axis angles in the SWWIM data are computed from $\overline{\mathbf{u}}$ during time periods when waves are relatively small $\left(H_{\text {sig }}<0.75\right)$ following Lentz et al. (2008). Calculating the principal axis based on all $\overline{\mathbf{u}}_{L}$ data results in differences of $1.2^{\circ}$ or less depending on the site.

In addition to velocity, time series of seawater density and wind are used at this site. Seawater density is calculated from temperature and conductivity data collected at the 7 $\mathrm{m}$ and $12 \mathrm{~m}$ sites using SBE-37 MicroCATs spaced at $2 \mathrm{~m}$ intervals throughout the water column. Wind speed and direction data are obtained from the MVCO beach meteorological mast, at a height $12 \mathrm{~m}$ above the surface. The wind data are rotated into the same coordinate system defined by principal axis of the 12-m site.

\section{b. Estimates of momentum balance terms}

The focus of this study is assessing the importance of the nonlinear terms in the momentum balances in equations (3) and (6). Since the nonlinear terms contain derivatives in the cross-shore direction, mooring data from two adjacent sites at different bottom depths are used to estimate this term. Vertical integrals of $\left(u_{L} v\right)$ are estimated at the inshore and offshore sites before taking their difference. The average of the two bottom depths is used for $D$. Where sufficient data are available, estimates of additional terms are averaged between the same two sites. At the FRF site, the momentum balance analysis focuses on the $6 \mathrm{~m}$ and $8 \mathrm{~m}$ sites due to availability of overlapping ADCP data. At the MVCO site, analysis focuses on data from the $7 \mathrm{~m}$ and $12 \mathrm{~m}$ sites.

Vertical integrals involving ADCP data, such as the depth integral of $v$ in equation (2), 
are estimated using the trapezoidal rule. Velocity is linearly interpolated from the bottom bin to zero at the seabed and extended from the top bin upward to the sea surface. The depth-averaged cross-shelf velocity $\bar{u}_{L}$ is subtracted from the cross-shelf velocity profile before estimating vertical integrals of $u_{L}$ and $\left(u_{L} v\right)$, which enforces a two-dimensional mass balance in which the net surface transport is zero. This isolates the depth-dependent circulation associated with wind-driven upwelling and downwelling, and is consistent with previous studies of the cross-shelf circulation at FRF and MVCO (Lentz, 2001; Fewings et al., 2008). In calculating the surface transport $U_{s}$ (equation 5), the depth of the first zero crossing, $z_{s}$, in the vertical profile of $u_{L}$ is estimated using linear interpolation. The vertical component of Lagrangian velocity, $w_{L}$ in equation (7), is estimated using the difference between $U_{s}$ at the two stations. The contribution of the temporal derivative in sea surface height was found to be negligible in the calculation of $w_{L}$ and is neglected. To estimate the vertical momentum flux term in equation (6), values of $v$ are interpolated to the zero crossing depth $z_{s}$ at each station and averaged. Time derivatives of local acceleration are estimated using a center difference method. Estimates of momentum balance terms are made from unfiltered (20 minute or hourly) data, then low-pass filtered to focus on subtidal time scales. Low pass filtered quantities are computed using a PL64 filter with a half-amplitude period of 33 hours (Rosenfeld, 1983).

Estimates of the nonlinear term at FRF are further restricted to time periods when the assumption of two dimensional mass balance is justified. We restrict analysis of the FRF data to time periods when the magnitude of the depth averaged cross-shelf velocity $\left|\bar{u}_{L}\right|<$ $0.03 \mathrm{~m} / \mathrm{s}$. The magnitude of $\bar{u}_{L}$ exceeds this threshold $3-8 \%$ of the time at the different sites at FRF. This does not occur during June-August at the $6 \mathrm{~m}$ or $8 \mathrm{~m}$ sites, where much of the detailed analysis is focused. Restricting the analysis to times when $\left|\bar{u}_{L}\right|<0.03$ $\mathrm{m} / \mathrm{s}$ excludes the effects of three-dimensional processes which could be important in the momentum balance but cannot be evaluated with the cross-shelf mooring arrays used in this study. 
Surface and bottom stress estimates are made using bulk formulas. Wind stress is computed using the quadratic drag coefficient formulation of Smith (1988). Two different formulations are used to estimate bottom stress from the ADCP observations at the FRF site. First, a quadratic drag law is used, assuming a logarithmic boundary layer. The roughness length, $z_{o}$ is estimated from $z_{o}=k_{s} / 30$, where $k_{s}$ is a grain roughness. The grain roughness is computed as $k_{s}=2.5 D$, using the median grain size $D=0.017 \mathrm{~cm}$ at Duck, NC (Lee et al., 2002). In terms of a drag coefficient $C_{D}=\left[\kappa / \ln \left(z / z_{o}\right)\right]^{2}$, where $\kappa$ is Von Karman's constant, the resulting value of $z_{o}=1.4 \times 10^{-5} \mathrm{~m}$ corresponds to $C_{D}=1.3 \times 10^{-3}$ at a height $1 \mathrm{~m}$ above the bed. The use of a constant $z_{o}$ based on grain roughness neglects effects of a rippled bed, wave-current interaction and near-bed stratification. However, this value is close to the value of $C_{D}=1.0 \times 10^{-3}$ obtained by Feddersen et al. (1998) from a best fit between wind stress and bottom stress seaward of the surf zone at Duck, NC. In addition to the quadratic drag law, a linear drag coefficient of $5 \times 10^{-4} \mathrm{~m} / \mathrm{s}$ is also tested for consistency with the study of Lentz et al. (1999). Since detailed measurements of the bottom boundary layer are not available to constrain bottom stress estimates in this study, these simple formulations are used for consistency with previous literature, and the implications of uncertainty in the physics will be discussed.

\section{Results}

\section{a. Description of variability over the inner shelf}

Basic descriptions of wind forcing, stratification and velocity are presented first to provide context for the momentum balance analysis. Stratification has the potential to influence nonlinear momentum fluxes by promoting the development of cross-shelf exchange and vertical shear. Density stratification, expressed as buoyancy frequency $N=\sqrt{-\frac{g}{\rho_{o}} \frac{\partial \rho}{\partial z}}$, exhibits a strong seasonal cycle at both the FRF and MVCO sites (Fig. 2a,b). Differences in the monthly means of stratification between the two locations are due in part to methodological differences. At MVCO, monthly means of stratification are estimated from den- 
sity differences at moored sensors between 1-4.5 $\mathrm{m}$ at the $7 \mathrm{~m}$ site, and between 1-9.5 $\mathrm{m}$ at the $12 \mathrm{~m}$ site (Fig. 2b, solid lines). At FRF, stratification is estimated from density differences between 1-7 $\mathrm{m}$ from CTD casts conducted during the day, when higher stratification is expected due to the daily cycle of surface heat flux (2a, solid lines). Using the climatology of the daily maximum at the $7 \mathrm{~m}$ site at $\mathrm{MVCO}$, in an attempt to account for daytime sampling bias and differences in bottom depth, still indicates that the FRF site is typically more stratified during all times of the year (Fig. 2b, dashed line). Weaker stratification at MVCO may be due to mixing driven by stronger tidal currents. At both locations, highest levels of stratification occur during the months of June-August. The analysis of nonlinear momentum fluxes focuses primarily on these months.

Differences in wind forcing between FRF and MVCO also contribute to differences in physical dynamics (Fig. 2c,d). At FRF, during the months of June-August, wind stress is most commonly oriented offshore (positive $\tau^{s x}$ ) and upwelling favorable (positive $\tau^{s y}$ ). At MVCO, wind stress is most commonly oriented with onshore $\tau^{s x}$, but upwelling favorable $\tau^{s y}$. Wind stresses are not strongly polarized in the alongshore direction at either site, unlike many locations on the US west coast where the winds are steered by coastline topography.

The relationship between alongshore wind stress and cross-shelf transport differs between FRF and MVCO during the stratified period of June-August. At FRF, periods of offshore and upwelling favorable wind stress are typically associated with offshore surface layer transport $U_{s}$, consistent with upwelling circulation (Fig. 3a). Reversals to onshore and downwelling favorable wind stress at this site are typically associated with onshore $U_{s}$. The relationship between wind forcing and cross-shelf transport is more complex at MVCO, where offshore $U_{s}$ is typically present during a wide range of wind conditions (Fig. 3b). Offshore $U_{s}$ at this site is observed during onshore and upwelling-favorable wind forcing, as well as reversals to offshore and downwelling favorable conditions. Weak onshore $U_{s}$ is present some of the time during onshore and downwelling favorable wind 
stress, and during events in which wind stress is directly onshore with no alongshore component. However, the magnitude of onshore $U_{s}$ at MVCO is not as high as that observed during similar wind conditions at FRF.

A subset of the FRF time series from 2013 is now used to describe wind forcing and circulation patterns at time scales of days-weeks (Fig. 4). In the next section, it will be shown that these circulation patterns influence the momentum balance through the cross-shelf divergence of nonlinear momentum fluxes. Data from the FRF site are used to present these patterns in time series form due to the relatively clear relationship between cross-shelf transport and wind stress (Fig. 3). During the 45-day time period from 13June to 28-July 2013, wind stress typically varies between offshore, upwelling-favorable conditions and onshore, downwelling favorable winds (Fig. 4a). Surface transport $U_{s}$ typically varies together at the three mooring sites from 5-8 m, increasing with offshore distance (Fig. 4b). The reduction of $U_{s}$ near the coast is a characteristic pattern of the inner shelf region. Strong vertical shear in the alongshore current, $\partial v / \partial z$, is also present during this time period at both the $6 \mathrm{~m}$ and $8 \mathrm{~m}$ sites (Fig. 4c). The vertical shear is estimated from differences between $2.0-7.5 \mathrm{~m}$ at the $8 \mathrm{~m}$ site, and between $2.0-5.0 \mathrm{~m}$ depth at the $6 \mathrm{~m}$ site. Positive $\partial v / \partial z$ at both sites is generally associated with offshore $U_{s}$, as well as offshore and upwelling favorable winds. The combination of vertical shear, cross-shelf exchange and cross-shelf variations in the circulation provide the necessary conditions for nonlinear terms to be potentially important in the alongshore momentum balance.

\section{b. Role of nonlinear terms in depth-averaged momentum balances}

The dynamical importance of the nonlinear momentum flux divergence is compared with other terms in the depth-averaged alongshore momentum balance (equation 3). Comparisons of the magnitude and timing of the different terms are first made using the subset of the time series at FRF (Fig. 4), then in a statistical analysis of all available data. The nonlinear term, estimated from the $6 \mathrm{~m}$ and $8 \mathrm{~m}$ sites at FRF, is positive during much of the 45-day period (Fig. 4d). When wind stress and the nonlinear term are both positive, 
nonlinear momentum fluxes associated with upwelling circulation play a role in balancing the wind stress. In this case, alongshore momentum is transferred to the ocean by the surface stress, but there is a net offshore flux of alongshore momentum. There are also events (e.g. at 22-June and 26-July) when the wind stress is downwelling-favorable, but the nonlinear term is still positive. In this case, a net onshore flux of negative alongshore momentum during downwelling reinforces negative $\tau^{s y}$ on the inner shelf.

The magnitude of the nonlinear term is comparable to other terms in the momentum balance. Although the nonlinear term does not completely balance the wind stress during the period of sustained upwelling-favorable winds from 24-June to 12-July, it is large enough to make a dynamically important contribution (Fig. 4d). Bottom stress, estimated using the logarithmic layer formulation, is also too small to balance wind stress during this upwelling-favorable period (Fig. 4e). In contrast, the magnitude of the bottom stress is larger than that of the wind stress during the downwelling favorable events at 22-June and 26-July. These patterns are consistent with the contribution of a positive nonlinear momentum flux divergence term during both upwelling and downwelling conditions.

Additional terms also play a role in the alongshore momentum balance. Acceleration is important during certain periods of fluctuating bottom stress, which indicate reversals in the direction of the alongshore flow (Fig. 4e). Estimates of the alongshore pressure gradient are unavailable in this study, but drops in practical salinity below 30 do occur (Fig. 4f), indicating the presence of a buoyant plume originating at the mouth of the Chesapeake Bay (Rennie et al., 1999; Lentz and Largier, 2006). The buoyant plume is associated with southeastward flow and an alongshore pressure gradient force in the negative $y$ direction. The timing of the low-salinity events indicates that the alongshore pressure gradient contributes to negative $\tau^{b y}$ during periods of weak or upwelling-favorable wind stress, and may also play a role during periods of large bottom stresses that exceed the downwellingfavorable wind stress, in addition to the nonlinear momentum flux divergence.

Since wind stress and bottom stress have previously been identified as the dominant 
terms in the alongshore momentum balance at FRF (Lentz et al., 1999), the role of the nonlinear term in modifying the balance between these two terms is examined using all of the available data at the $6 \mathrm{~m}$ and $8 \mathrm{~m}$ sites during June-August. The alongshore wind stress is compared to three response variables: 1) bottom stress only (Fig. 5, BS); 2) the sum of bottom stress and nonlinear momentum flux divergence (Fig. 5, BS+NL); and 3) the sum of bottom stress, nonlinear momentum flux divergence and local acceleration (Fig. 5, BS+NL+A). Similar correlation coefficients of $r=0.72-0.77$ are obtained for all three response variables, although the correlations are slightly lower when the nonlinear term is included in the response. Using a linear drag coefficient following Lentz et al. (1999) yields a similar range of correlation coefficients, $r=0.72-0.75$ (not shown). Despite the similarity of the correlation coefficients obtained with different response variables, examining bin averages of the response by wind stress shows that the nonlinear term does have an impact on the dynamical balance, and that this impact is greater than that of the acceleration term (Fig. 5). Inclusion of the nonlinear terms results in a closer balance with the wind stress. Consistent with the time series variability described above, the magnitude of the response is reduced for downwelling-favorable wind stress and increased for upwelling-favorable wind stress when the nonlinear term is included. These asymmetric changes under different wind conditions are not captured by linear regression analysis and are not improved by tuning bottom drag coefficients.

To examine the role of wind forcing, the dependence of the nonlinear term on wind stress is compared at the FRF and MVCO locations, focusing primarily on the stratified period of June-August. At FRF, the response to wind stress is typically positive regardless of whether $\tau^{s y}$ is positive or negative (Fig. 6a), consistent with the time series described above at the same sites on the $6 \mathrm{~m}$ and $8 \mathrm{~m}$ isobaths (Figs. 4d, 5). The slopes of the regressions between wind stress and nonlinear terms have the same sign when other pairs of sites are examined; positive slopes are obtained for upwelling favorable wind stress and negative slopes are obtained for downwelling favorable wind stress (Table 1). However, 
the results obtained for downwelling favorable wind stress are less robust since the regression slopes are significantly different from zero for only three of the five pairs of sites. In addition, the regression slope obtained for the shallowest sites at $5 \mathrm{~m}$ and $6 \mathrm{~m}$ during upwelling favorable wind stress is only marginally significant, possibly due to the difficulty in observing small differences in the momentum flux between sites in close proximity. In general, these results from FRF during stratified period of June-August show that the nonlinear term is typically positive regardless of wind direction, but the correlation between the nonlinear term and the alongshore wind stress is more consistent during periods of upwelling favorable wind stress.

At MVCO, there is a different relationship between wind stress and the nonlinear term. The nonlinear term at MVCO is positive for upwelling-favorable wind stress and negative for downwelling-favorable wind stress (Fig. 6b). This different response to downwelling-favorable winds at MVCO compared with FRF is consistent with the differences in surface transport and cross-shelf wind stresses. The magnitude and direction of the nonlinear term depends on both cross-shelf exchange, which can be quantified using the surface transport, and the vertical structure of the alongshore flow, which can be quantified using the vertical shear. At MVCO, an offshore surface transport is typically present even when the alongshore component of wind stress is downwelling-favorable (Fig. 4d). The strength and direction of vertical shear in the alongshore current, however, is sensitive to the alongshore wind stress (Fewings et al., 2008). Variability of vertical shear in response to alongshore wind stress and cross-shore density gradients will be examined in greater detail in Section 2.d.

The magnitude of the nonlinear term relative to the wind stress also differs between locations. The regression slope of 0.15 between the two terms at MVCO during JuneAugust is smaller than those obtained at FRF during upwelling favorable winds ((Fig. 6, Table 1). Comparing the standard deviations of the two terms also shows that the nonlinear term has a greater contribution to the momentum balance at FRF than MVCO (Fig. 7). 
There are also consistent differences between seasons at each location (Fig. 7). At both locations, the relative importance of the nonlinear term decreases during the months of January-March when the water column is more weakly stratified (Fig. 2).

\section{c. Role of nonlinear terms in surface layer momentum balances}

The momentum balance integrated over the surface layer (equation 6) provides a framework for linking nonlinear momentum fluxes to cross-shelf exchange and turbulent stresses. As in the previous section, the roles of the nonlinear terms are compared between FRF and MVCO. The cross-shelf flux divergence is combined with the vertical flux to show the net effect of nonlinear momentum fluxes integrated over the surface layer.

During the stratified months of June-August at FRF and MVCO, the alongshore wind stress term is compared with two different response variables in the momentum balance of the surface layer: 1) the Coriolis force $\left(f U_{s}\right)$ and 2$)$ the nonlinear terms. At FRF, the Coriolis force is correlated with the alongshore wind stress during both upwelling-favorable and downwelling-favorable conditions (Fig. 8a). The regression slopes are significantly less than one in each case, indicating that surface transport is significantly reduced from the theoretical Ekman transport $U_{E k}=\tau^{s y} / \rho_{o} f$ expected in deeper water. At MVCO, the regression slope between the Coriolis force and wind stress during upwelling-favorable conditions is smaller than at FRF (Fig. 8c). During downwelling-favorable wind stress at MVCO, the regression slope is only marginally statistically significant but negative (Fig. 8c). This pattern is consistent with the persistent offshore transport that occurs at this location, even during downwelling favorable wind stress (Fig. 3b).

At both locations, inclusion of the nonlinear terms impacts the alongshore momentum balance of the surface layer. At FRF, similar to the depth-averaged momentum balance shown in Section 4.b, the relationship between the wind stress and the nonlinear terms changes depending on the direction of the alongshore wind stress (Fig. 8b). During upwelling-favorable winds at FRF, the positive regression slope between the wind stress and the nonlinear terms $(0.35 \pm 0.15)$ indicates that a substantial fraction of the momen- 
tum put into the ocean by wind stress is transferred offshore by the nonlinear momentum fluxes associated with the upwelling circulation, in addition to being transferred downward by the turbulent stress at the base of the surface layer (Fig. 8a). Based on the regression coefficient, the impact of nonlinear momentum fluxes exceeds that of the Coriolis force. Under downwelling favorable conditions at FRF, the regression slope is only marginally different from zero (Fig. 8b). In this case, positive values of the nonlinear term are consistent with a transfer of momentum from offshore by the nonlinear momentum fluxes associated with the downwelling circulation, as well as an enhanced interior stress whose magnitude exceeds that of the wind stress.

The nonlinear terms have a less significant impact on momentum balance of the surface layer at MVCO, and once again there are differences from the dynamics observed at FRF. At MVCO, the nonlinear terms tend to be positive during upwelling favorable winds and negative during downwelling favorable winds (Fig. 8d). The regression slope is significant, but the correlation of $r^{2}=0.27$ indicates substantial scatter in the relationship. A piece-wise linear fit is only significant for the negative values of $\tau^{s y}$. However, the overall trend is consistent with the depth averaged balance at the same site (Fig. 6b). Unlike FRF, the nonlinear momentum fluxes at MVCO tend to balance the alongshore wind stress during both upwelling-favorable and downwelling-favorable conditions. The presence of persistent offshore surface transport at MVCO, even when the alongshore component of wind stress is downwelling-favorable, alters the relationship between the nonlinear terms and alongshore wind stress at this site. The influence of cross-shelf wind stress on surface transport likely contributes to the variability of the nonlinear term, which depends in part on the strength of cross-shore circulation.

\section{d. Role of density structure and processes influencing vertical shear}

Density stratification and cross-shelf density gradients can influence nonlinear momentum fluxes through their roles in governing mixing, cross-shelf exchange and vertical shear. This section specifically focuses on the processes governing vertical shear in the 
alongshore flow, which must be present for the nonlinear term to contribute to the alongshore momentum balance. There are several potential mechanisms for the generation of vertical shear, including thermal wind balance and frictional stresses. Hypothetical predictions of vertical shear involving the cross-shelf density gradient and surface wind stress are now examined under different levels of stratification.

The hypothetical predictions are evaluated at the $7 \mathrm{~m}$ and $12 \mathrm{~m}$ sites at MVCO. The analysis focuses on depths where density and velocity data are available at both of these sites. Vertical shear is computed from velocity differences between $3 \mathrm{~m}$ and $5 \mathrm{~m}$ depths. The horizontal density gradient is computed from averages of density observations at depths of $3 \mathrm{~m}$ and $5 \mathrm{~m}$ at each site. Results are categorized based on the buoyancy frequency $N$, calculated from averages of the $7 \mathrm{~m}$ and $12 \mathrm{~m}$ sites. A value of $N=0.01$ $\mathrm{s}^{-1}$ is chosen to characterize periods of relatively weak and strong stratification. Based on climatological averages (Fig. 2b), periods of $N<0.01 \mathrm{~s}^{-1}$ are typical during OctoberMarch.

i. Geostrophic shear and thermal wind balance If the cross-shelf momentum balance is geostrophic, the vertical shear is proportional to the cross-shelf density gradient and determined by thermal wind balance

$$
\frac{\partial v}{\partial z}=-\frac{g}{f \rho_{o}} \frac{\partial \rho}{\partial x}
$$

At MVCO, the cross-shelf density gradient $\partial \rho / \partial x$ is typically positive (density increases offshore), which is consistent with negative $\partial v / \partial z$ in a hypothetical thermal wind balance (Fig. 9a). During periods of weak stratification, $\partial \rho / \partial x$ is relatively small and sometimes negative. The two terms in the thermal wind balance are weakly correlated during both strongly stratified periods $(r=0.44, p<0.001$, slope $=0.55)$ and weakly stratified periods $(r=0.51, p=0.03$, slope $=0.37)$. However, there are times when there is clear disagreement. In particular, thermal wind balance fails to explain positive values of $\partial v / \partial z$. It 
should be noted that comparing the terms of the thermal wind balance is challenging using measurements from two moorings. The estimates of vertical shear at the $7 \mathrm{~m}$ and $12 \mathrm{~m}$ sites are only weakly correlated with each other $(r=0.53$ during stratified periods, $r=0.55$ during unstratified periods) and small-scale density fronts may be unresolved. The agreement with thermal wind balance is not improved when the vertical shear from individual sites are used in place of the average, except when the $7 \mathrm{~m}$ site is used during unstratified periods (increasing $r$ slightly from 0.51 to 0.55 ). Although unresolved gradients may be a factor, estimates from the available measurements suggest that there is substantial ageostrophic shear which is associated with deviations from thermal wind balance.

ii. Wind-supported shear In addition to geostrophic processes, which are inviscid and depend on the Earth's rotation, vertical shear can also be associated with the presence of turbulent stresses in the water column. To test whether the magnitude of the observed vertical shear $\partial v / \partial z$ is consistent with generation of frictional stresses by the wind, a hypothetical relationship based on a simple form of the eddy viscosity $A$ is considered. Eddy viscosity over the inner shelf is expected to vary as a function of stratification, surface buoyancy fluxes, advection of the density field and distance from the boundaries. Although the data used in this study cannot resolve the complexity of turbulent stresses over the inner shelf, a simplified form of the eddy viscosity is used to compare the strength of hypothetical wind-supported shear relative to the geostrophic shear. In modeling a river plume under downwelling-favorable wind stress, Chen and Chen (2017) found the vertical shear to be consistent with the relationship

$$
\frac{\partial v}{\partial z}=\frac{\tau^{s y}}{\rho_{o} A}
$$

where $A=\kappa u_{*} h / 6$, and $u_{*}=\sqrt{\left|\tau^{\mathrm{s}}\right| / \rho_{o}}$ is a friction velocity based on the magnitude of the surface stress $\left|\tau^{\mathbf{s}}\right|$. This provides an estimate of the depth-averaged shear when the alongshore stress $A \partial v / \partial z$ is constant throughout the water column and determined 
completely by the wind stress. The choice of constant $A$ is consistent with the depthaverage of a parabolic vertical profile of $A$ (Chen and Chen, 2017). The hypothetical windsupported shear in equation (9) is expected to be most relevant when the water column is unstratified.

Like the geostrophic shear, the hypothetical wind-supported shear alone cannot completely explain the observations (Fig. 9b). There is a significant correlation during periods of weak stratification $(r=0.74, p<0.001$, slope $=0.40)$, but the expression for windsupported shear in equation (9) does not account for the presence of negative $\partial v / \partial z$ during weak wind stress and the regression slope suggests that this relationship underestimates the observed vertical shear. During stratified periods, the terms are also correlated $(r=$ $0.71, p<0.001$, slope $=1.41)$ but there are large discrepancies between the magnitudes of the observed shear and theoretical predictions. Some of the negative $\partial v / \partial z$ values that are inconsistent with the magnitude of the wind-supported shear can be explained by thermal wind shear (Fig. 9a). Positive values of $\partial v / \partial z$ that cannot be explained by thermal wind balance during periods relatively strong stratification occur during periods of positive $\tau^{s y}$ and strong wind-supported shear (9b). It is therefore likely that the observed vertical shear results from the combined effects of geostrophic and frictional processes.

iii. Combined geostrophic and wind-supported shear Cross-shelf density gradients and wind stress both likely play a role in determining the strength and direction of the vertical shear, and therefore the nonlinear fluxes of alongshore momentum. Stratification also likely plays an important role in modulating vertical shear. Although thermal wind balance does not completely explain the vertical shear at MVCO, the residual is significantly correlated with the alongshore wind stress during stratified periods (Fig. 10a, $r$ $=0.62, \mathrm{p}<0.001)$. Over the same range of alongshore wind stress values, variations in vertical shear and the thermal wind balance residual are significantly reduced during unstratified periods when cross-shelf density gradients are also relatively small (Figs. 9, 10a). These results suggest that the wind stress is most effective at generating ageostrophic 
shear over the inner shelf when the water column is stratified.

The influences of stratification and cross-shelf density gradients on vertical shear are important factors governing the dynamical importance of the cross-shelf momentum flux divergence. The presence of vertical shear is essential for the nonlinear term in equation (3) to have a role in the depth-averaged alongshore momentum balance. We conclude this section by revisiting the relationship between the wind stress and the nonlinear term at MVCO (Fig. 6b) and examining the influence of stratification. Consistent with the results from June-August, the relationship between alongshore wind stress and vertical shear, combined with upwelling circulation, leads to a weak but significant correlation between along-shelf wind stress and the nonlinear term at MVCO when the water column is stratified (Fig. 10b, $r=0.44, p<0.001$, slope $=0.18$ ). However, during weakly stratified time periods, the magnitude of the nonlinear term is much smaller over a similar range of $\tau^{s y}$ values. Although the relationship between alongshore wind stress and the nonlinear term differs between locations (Fig. 6), vertical shear is expected to vary in response to thermal wind balance and alongshore wind stress at all inner shelf locations.

\section{Discussion}

\section{a. Circulation patterns associated with nonlinear momentum fluxes}

To summarize circulation patterns associated with nonlinear momentum fluxes over the inner shelf, conceptual models are presented based on results from this study and previous studies at the same locations (Fig. 11).

i. North Carolina inner shelf Flow patterns and dynamics associated with upwelling circulation over the inner shelf are first described based on observations at the FRF site (Fig. 11a). The most common wind pattern at FRF in North Carolina is upwelling favorable and offshore (Fig. 2c). This type of wind forcing is strongest before the passage of an atmospheric front and is also associated with the strongest surface heat fluxes from the atmosphere to the ocean (Austin and Lentz, 1999). As observed by Lentz (2001), the 
magnitude of offshore $U_{s}$ increases with water depth but typically remains less than the theoretical deep water Ekman transport $U_{E k}$ at sites where water depth $h<10 \mathrm{~m}$ (Fig. $4 \mathbf{b}, 8 \mathrm{a})$. The positive divergence of cross-shelf surface transport $\partial U_{s} / \partial x$ is consistent with upward vertical velocity $w_{L}$ over the inner shelf. Hydrographic observations offshore of FRF during upwelling-favorable wind forcing in August show a shoaling of the thermocline near shore (Austin and Lentz, 1999; 2002; Cudaback and Largier, 2001), which is also consistent with the presence of an upwelling circulation.

Upwelling-favorable and offshore wind forcing at FRF is also often associated with strong positive vertical shear $\partial v / \partial z$ (Fig. 11a). The vertical shear reaches similar values at different mooring sites at FRF (Fig. 4c). The positive sign of $\partial v / \partial z$ is consistent with thermal wind balance associated with negative $\partial \rho / \partial x$ as the thermocline shoals and cold, dense water is upwelled near the coast. Density time series for estimating $\partial \rho / \partial x$ are not available during the time period analyzed in this study, but previous observations show significant correlations between the two terms in the thermal wind balance (Lentz et al., 1999). However, Lentz et al. (1999) found weaker agreement with thermal wind balance at the shallowest sites $(8-13 \mathrm{~m})$, and the largest disagreements appear to be during times when $\partial v / \partial z$ is positive. In addition to geostrophic thermal wind shear, it is therefore possible that wind forcing contributes directly to vertical shear by generating turbulent stresses.

The circulation patterns established during upwelling-favorable and offshore wind stress at FRF (Fig. 11a) lead to a divergence of the cross-shelf flux of alongshore momentum, a nonlinear process that influences the alongshore momentum balance. The combination of offshore $U_{s}$ and positive $\partial v / \partial z$ creates a net offshore flux of positive alongshore momentum when integrated over the water column, $\int_{-h}^{\eta}\left(u_{L} v\right) d z$, since the onshore return flow in the lower layer is associated with relatively small $v$ compared with the surface layer. This flux increases with offshore distance as offshore transport increases and as the surface-to-bottom velocity difference increases for similar $\partial v / \partial z$. This mechanism is sim- 
ilar to that described by Lentz and Chapman (2004) for upwelling conditions at mid-shelf locations. However, the dynamics are modified over the inner shelf because $U_{s}$ changes with offshore distance and there is no clear separation between the surface and bottom boundary layers.

During downwelling-favorable and onshore wind forcing, the circulation patterns are essentially reversed over the inner shelf at FRF (Fig. 11b). This type of wind forcing commonly follows the passage of atmospheric fronts (Austin and Lentz, 1999). The onshore surface layer transport $U_{s}$ is reduced from $U_{E k}$, and there is a convergence $\partial U_{s} / \partial x<0$ consistent with downward $w_{L}$ (Lentz, 2001). Hydrographic data indicate the presence of a downwelling front, with water of uniform temperature onshore of the front (Austin, 1999; Cudaback and Largier, 2001). The cross-shelf circulation associated with downwelling over the inner shelf is time-dependent, and has been shown in some cases to shut down after the downwelled isotherms move offshore (Lentz, 2001). However, the time-dependent density structure can be complicated by the arrival of salinity associated with the Chesapeake Bay freshwater plume, which lags negative (downwelling-favorable) $\tau^{s y}$ (Cudaback and Largier, 2001). During weak or moderate downwelling-favorable wind stress, the plume can promote stratification onshore of the downwelled isotherms and create a region of positive $\partial \rho / \partial x$ and negative $\partial v / \partial z$ (Cudaback and Largier, 2001), which is qualitatively consistent with thermal wind balance. The vertical shear in the alongshore flow is enhanced during periods of downwelling-favorable wind stress, which promotes mixing of the plume during periods of relatively strong downwelling-favorable wind stress (Lentz and Largier, 2006). The presence of mixing in the plume during both upwelling-favorable and downwelling-favorable wind stress leads to ageostrophic shear and deviations from thermal wind balance (Mazzini et al., 2019).

The circulation patterns associated with downwelling winds at FRF (Fig. 11b) lead to a positive momentum flux divergence. This nonlinear term in the depth-averaged momentum balance has the same positive sign during both upwelling and downwelling (Fig. 6a). 
This is generally consistent with the idealized modeling study of Kuebel Cervantes et al. (2004), in which the nonlinear terms make a mean positive contribution inshore of an upwelling front under periodic wind forcing. Time dependence of the cross-shelf circulation, and the presence of a freshwater plume, likely contribute to variability of this term during downwelling-favorable winds.

ii. New England inner shelf At MVCO, the relationship between wind forcing and nonlinear momentum flux divergence is less straightforward. During the stratified season of June-August, winds are often either upwelling-favorable and onshore, or downwellingfavorable and offshore (Fig. 2d). The wind stress components $\tau^{s y}$ and $\tau^{s x}$ therefore often oppose each other in their contributions to $U_{s}$. Offshore $U_{s}$ is present at MVCO during a wide range of forcing conditions, including weak wind stress, consistent with the presence of a persistent mean upwelling circulation that has been previously identified at this site (Fewings et al., 2008; Fewings and Lentz, 2011). Warmer, lighter water is typically present near shore, consistent with observations of positive $\partial \rho / \partial x$ (Fig. 9a). Fewings and Lentz (2011) show that the presence of warmer and lighter water near shore is consistent with a combination of surface heat flux warming shallow waters and strong vertical mixing. Compared with the North Carolina shelf, the New England shelf is characterized by stronger tides, facilitating strong vertical mixing.

In the alongshore component of velocity, mean negative (westward) $\bar{v}$ is present, likely due to a combination of a large-scale mean alongshore pressure gradient (Lentz, 2008b; $\mathrm{Xu}$ and Oey, 2011) and tidal rectification near shoals to the east of the mooring array (Ganju et al., 2011; Kirincich et al., 2013). However, conditional averages of velocity during alongshore wind forcing in winter months show that positive $\tau^{s y}$ in the range $0.5-$ 1.0 $\mathrm{Pa}$ is sufficient to reverse the alongshore flow to positive $v$, and create positive $\partial v / \partial z$ (Fewings et al., 2008). Conditional averages of velocity at MVCO during combined $\tau^{s y}$ and $\tau^{s x}$ forcing and weak stratification show $v$ in the same direction as the alongshore component of wind stress (Kirincich, 2013). This pattern is consistent with model results 
which show that alongshore wind stress is more effective than cross-shelf wind stress at driving alongshore velocity (Tilburg, 2003). Reversals in alongshore velocity can occur without a corresponding reversal in $U_{s}$ at this location. However, prior studies that have examined the vertical structure of alongshore currents under different wind conditions at MVCO have primarily focused on periods of weak stratification.

In the stratified season at MVCO, during upwelling-favorable and onshore wind forcing, circulation patterns are often characterized by offshore $U_{s}$ and positive $\partial v / \partial z$ (Fig. 11c). The presence of positive $\partial v / \partial z$ is inconsistent with thermal wind balance and positive $\partial \rho / \partial x$ (Fig. 9a, Section 2.d.i). However, the presence of positive $\partial v / \partial z$ can be explained by ageostrophic shear generated by the wind stress (Figs. 9b, 10). Deviations from thermal wind balance are likely to occur over the inner shelf, where turbulent stresses occur throughout the water column, which suggests that the theory developed for mid-shelf locations by Lentz and Chapman (2004) does not fully explain the dynamics over the inner shelf.

During downwelling-favorable and offshore wind forcing at MVCO, circulation patterns are characterized by offshore $U_{s}$ and negative $\partial v / \partial z$ (Fig. 11d). The presence of negative $\partial v / \partial z$ can be attributed to a combination of thermal wind balance and windinduced shear (Figs. 9, 10a). During downwelling favorable winds at MVCO, this nonlinear term tends to balance negative $\tau^{s y}$ due to a net offshore flux of negative momentum (Figs. 6b, 8d). This differs dramatically from downwelling-favorable conditions at FRF, where a net onshore flux of negative momentum tends to reinforce the wind stress. These results show that the contribution of the nonlinear momentum flux divergence depends on the background circulation and cross-shelf component of wind stress, in addition to the along-shelf wind stress.

\section{b. Dynamical importance of nonlinear momentum fluxes}

The observed relationships between the nonlinear terms and wind stress at FRF are qualitatively consistent with the two-dimensional modeling study of Kuebel Cervantes 
et al. (2003), which includes realistic wind forcing and surface fluxes during the time period of the 1994 CoOP program. During upwelling favorable wind conditions in this model study, the regression slopes between the nonlinear and wind stress terms in the depth-averaged momentum balance are 0.26 at $4 \mathrm{~m}$ and 0.33 at $8 \mathrm{~m}$. These regression slopes are smaller than the value of 0.57 found in this study, but still account for an important component of the momentum balance. During downwelling-favorable conditions, the slopes obtained by Kuebel Cervantes et al. (2003) are negative, but with values of -0.037 to -0.035 , which are much smaller in magnitude than found here from the observations. Similar to the observational estimates in this study (Fig. 5), the modeled momentum balance shows different relationships between surface stress and bottom stress depending on the sign of the alongshore wind stress. Neither this study nor the model study of Kuebel Cervantes et al. (2003) account for the alongshore pressure gradient term in the momentum balance, which Lentz et al. (1999) found to improve closure of the momentum balance in the 1994 CoOP observations, although it was uncorrelated with the alongshore wind stress. In addition to influencing the alongshore pressure gradient, the Chesapeake plume also influences the FRF site by promoting density stratification and thermal wind shear (Rennie et al., 1999; Cudaback and Largier, 2001). The presence of salinity stratification likely increases cross-shelf exchange and alters the position of the downwelling front, which may account for some of the differences between this study and the model study of Kuebel Cervantes et al. (2003).

At MVCO, the nonlinear terms play a relatively minor role in balancing the alongshore wind stress. In a previous study of the alongshore momentum balance at this site, which does not include estimates of the nonlinear terms, Fewings and Lentz (2010) demonstrated a dominant balance between the wind stress and the alongshore pressure gradient, with bottom stress making a secondary contribution. Observations of the alongshore pressure gradient are not available during the time period of the SWWIM observations used in this study. However, the regression slope of 0.15 between the wind stress and 
the nonlinear term found in this study is significantly smaller than the regression slope of 0.9 between the wind stress and alongshore pressure gradient found by Fewings and Lentz (2010). Although it is clearly not the dominant mechanism for balancing the wind stress at MVCO, this contribution of the nonlinear term is likely greatest during periods of strong stratification, when cross-shelf exchange and vertical shear are strongest.

\section{c. Estimation of nonlinear momentum flux divergence from a single moor-} ing

It is possible to estimate the nonlinear term based on a single mooring, rather than a pair of moorings, since there can be no flux of momentum at the coastal boundary. This type of estimate has been used to justify neglecting the nonlinear term in previous studies of the alongshore momentum balance at MVCO (Fewings and Lentz, 2010; Kirincich, 2013). If the vertically integrated momentum flux decreases linearly to the coast at $x=0$, the momentum flux divergence can be approximated as

$$
\frac{\partial}{\partial x} \int_{-h}^{0}\left(u_{L} v\right) d z \approx \frac{1}{x} \int_{-h}^{0}\left(u_{L} v\right) d z
$$

The approximation in equation (10) was used by Lentz and Chapman (2004) to estimate the momentum flux divergence from single moorings at mid-shelf sites. Over the inner shelf, the observed variability of the depth-integrated momentum flux is consistent with a monotonic decrease towards the coast (Fig. 12). Standard deviations of the depthintegrated momentum flux during June-August are smaller at shallower water depths at both FRF and MVCO. The standard deviations are larger at FRF than MVCO at similar water depths, consistent with a greater importance of the momentum flux divergence term over the North Carolina inner shelf.

To test the validity of the approximation in equation (10), the estimates made from pairs of moorings are compared with the approximation estimated from the deeper mooring only (Fig. 13a). The approximation is strongly correlated with the estimates made 
from the pairs of moorings at FRF $(r=0.92)$ and MVCO $(r=0.95)$ during the stratified months of June-August. However, the approximation in equation (10) underestimates the magnitude of the nonlinear term estimated from pairs of moorings, as indicated by regression slopes of 2.1 at FRF and 1.5 at MVCO. This suggests that the assumption of a linear decrease of the vertically integrated momentum flux near the coast may not be valid. This is confirmed by comparing the standard deviation of the depth-integrated momentum flux at different sites (Fig. 12). The variability is consistent with a quadratic increase with water depth, from zero at the coast, which would result in an underestimate if a linear increase is assumed. The approximation in equation (10) can be used to obtain an order of magnitude estimate of the nonlinear term, and to examine how the nonlinear term varies in time with the wind stress or other forcing, but it may represent a lower bound on the value over the inner shelf.

\section{d. Factors governing importance of nonlinear momentum fluxes}

The dynamical impact of the nonlinear term is potentially significant, but this impact varies both in time and between different inner shelf locations. To assess the factors that govern the overall importance of nonlinear momentum fluxes, a scaling is developed based on the bottom slope, surface transport and vertical shear. The expected role of the nonlinear term in the physical dynamics of the inner shelf is then discussed based on these commonly observed parameters.

The scaling analysis assumes linear vertical profiles of $u_{L}$ and $v$,

$$
\begin{gathered}
u_{L}(z)=\frac{4 U_{s}}{h}\left(1+\frac{2 z}{h}\right), \\
v(z)=v_{s}+\frac{\partial v}{\partial z} z
\end{gathered}
$$

where $v_{s}$ is the surface velocity at $z=0$. The linear cross-shelf velocity profile in equation (11) describes a two-layer flow that satisfies two-dimensional mass balance, $\bar{u}_{L}=0$. 
With the vertical structure of the velocity given by equations (11) and (12), the verticallyintegrated cross-shelf flux of alongshore momentum is

$$
\int_{-h}^{0}\left(u_{L} v\right) d z=\frac{2}{3} U_{s} \frac{\partial v}{\partial z} h .
$$

Three further simplifications are made about the cross-shelf structure of the circulation.

First, the ratio of the surface transport $U_{s}$ to the theoretical Ekman transport $U_{E k}$ is proportional to the ratio of the water depth $h$ to the boundary layer depth $\delta_{s}$, so that $U_{s} \propto U_{E k} h / \delta_{s}$ (Lentz and Fewings, 2012). Over the inner shelf, surface transport is reduced where the surface and bottom boundary layers overlap and $h<2 \delta_{s}$ (Lentz and Fewings, 2012). If the vertical shear $\partial v / \partial z$ and boundary layer depth $\delta_{s}$ are independent of $h$, the depthintegrated flux then depends on $h^{2}$, consistent with the observed variability (Fig. 12). Second, a constant bottom slope is assumed so that $h=\alpha x$. With a constant bottom slope $\alpha$, the surface transport increases with cross-shelf distance $U_{s} \sim U_{E k} \alpha x / \delta_{s}$. Third, the vertical shear $\partial v / \partial z$ is assumed to be independent of $h$. With these simplifications, the vertically integrated momentum flux in equation (13) is proportional to $x^{2}$, not $x$ as assumed in the approximation in equation (10). Using these assumptions of the cross-shelf structure, the divergence of the nonlinear momentum flux is

$$
\frac{\partial}{\partial x} \int_{-h}^{0}\left(u_{L} v\right) d z=\frac{4}{3} \alpha U_{s} \frac{\partial v}{\partial z}
$$

This scaling highlights the three main factors that influence the magnitude and direction of the momentum flux divergence: 1) the cross-shelf transport $U_{s}, 2$ ) the vertical shear $\partial v / \partial z$, and 3) the bottom slope $\alpha$. Note that the expression for the divergence of the nonlinear momentum flux in equation (14) does not change if the surface transport is driven primarily by the cross shelf component of the wind stress so that $U_{s} \propto-V_{E k} h / \delta_{s}$, where $V_{E k}=-\tau^{s x} / \rho_{o} f$, as expected for shallow depths $h<\delta_{s}$ (Lentz and Fewings, 2012). In both cases, the surface transport increases linearly with water depth $h$ in this 
simplified scenario. If the alongshore flow is in geostrophic balance, the vertical shear $\partial v / \partial z$ is related to the cross-shelf density gradient through thermal wind balance, as in equation (8). However, the presence of turbulent stresses can introduce ageostrophic shear. Ageostrophic shear contributes significantly to the total vertical shear in wind forced river plumes (Chen and Chen, 2017; Mazzini et al., 2019). Estimates of the ageostrophic shear at MVCO in this study are correlated with the alongshore wind stress at MVCO during stratified conditions (Fig. 10a). It is therefore possible that a turbulent thermal wind balance, in which geostrophic shear is modified by turbulent stresses, often applies over the inner shelf where the water depth and boundary layer thickness are comparable.

To test whether the scaling in equation (13) summarizes the key dynamics of momentum flux divergence over the inner shelf, estimates of the right-hand side are compared with the momentum flux divergence diagnosed from pairs of moorings at FRF and MVCO (Fig. 13b). Estimates of $U_{s}$ and $\partial v / \partial z$ are obtained from the deeper mooring site in each pair, while the bottom slope between the mooring pair at each location is used for $\alpha$. The scaling is significantly correlated with the nonlinear term, but overestimates the magnitude at both FRF $(r=0.72, \mathrm{p}<0.001$, slope $=0.72)$ and MVCO $(r=0.58, \mathrm{p}<0.001$, slope $=0.44)$. The scaling is consistent with the much greater range in magnitude of the nonlinear term at the FRF site compared with MVCO. Despite the highly simplified vertical and cross-shelf structure on which it is based, the simple scaling agrees reasonably well with the more detailed observational estimates, and can therefore be used to discuss how different aspects of inner shelf circulation and site characteristics influence the role of nonlinear processes.

To compare the importance of the nonlinear term at different inner shelf locations, it is useful to relate its magnitude to the wind stress. The dynamical role of the nonlinear term in the momentum balance can be summarized as a fraction of the alongshore wind stress term, 


$$
\frac{\frac{\partial}{\partial x} \int_{-h}^{0}\left(u_{L} v\right) d z}{\left(\frac{\tau^{s y}}{\rho_{o}}\right)}=\frac{4}{3} \frac{\alpha}{f} \frac{U_{s}}{U_{E k}} \frac{\partial v}{\partial z} .
$$

The fraction of theoretical Ekman transport in the surface layer, $U_{s} / U_{E k}$, becomes part of this non-dimensional number. Close to the coast, the fraction of theoretical Ekman transport approaches zero. In the absence of an alongshore pressure gradient, the wind stress is rapidly balanced by bottom friction in these shallow depths. At the boundary of the inner shelf and mid shelf, where $U_{s} / U_{E k}$ approaches $\sim 1$, the role of the nonlinear term is governed by $\alpha, f$ and $\partial v / \partial z$.

At the boundary of the inner shelf and mid shelf, the relationship between the nonlinear term and the wind stress shares similarities with the theory developed by Lentz and Chapman (2004). This theory is based on assumptions that 1) the surface transport is equal to the theoretical Ekman transport, 2) thermal wind balance is valid, and 3) there is a relationship between the cross-shelf density gradient $\partial \rho / \partial x$ and the stratification $\partial \rho / \partial z$ associated with isopycnals shoaling upward towards the coast. With these assumptions, the role of the nonlinear term in equation (15) could be summarized by the slope Burger number $S=N \alpha / f$ as in Lentz and Chapman (2004). Although the theory of Lentz and Chapman (2004) is based on a three-layer cross-shelf circulation structure, the presence of an inviscid interior between the surface and bottom boundary layers is not necessary for the nonlinear term to be important. However, a theory based on $S$ may not be appropriate for inner shelf locations, which differ in important ways from the mid-shelf locations in eastern boundary upwelling systems examined by Lentz and Chapman (2004). At MVCO, there is positive cross-shelf density gradient $\partial \rho / \partial x$ and isopycnals slope downward toward the coast even during periods of upwelling-favorable $\tau^{s y}$, which is inconsistent with the upward-sloping isopycnals assumed by Lentz and Chapman (2004). Kirincich and Barth (2009b) found that the importance of the nonlinear term in balancing the wind stress varied at different inner-shelf sites along the same isobath, due to differences in $\partial v / \partial z$ at 
sites with similar stratification. In addition, compared with mid-shelf sites, thermal wind balance is less well established over the inner shelf. Hydrographic sections and mooring time series do show consistency with thermal wind balance in shallow water (Lentz et al., 1999; Garvine, 2004; Kirincich and Barth, 2009a), indicating that it should play a strong role in determining the vertical shear. At $\mathrm{MVCO}$, thermal wind balance partially explains variability in $\partial v / \partial z$, but does not account for positive $\partial v / \partial z$ during upwelling-favorable wind stress (Section 4.d). Thermal wind balance may be more important at FRF where stratification is stronger and $\partial v / \partial z$ varies over a wider range, although Lentz et al. (1999) found this relationship to be weakest in shallow water.

Comparing the FRF and MVCO locations based on the three key factors of bottom slope, surface transport and vertical shear helps explain differences in the magnitude and relative importance of the nonlinear terms at each site. The regression slope between the nonlinear term and the wind stress is 0.57 at FRF during upwelling-favorable wind stress, and 0.15 at MVCO over all wind forcing conditions (Fig. 6). Differences in bottom slope between the two locations, $\alpha=6.4 \times 10^{-3}$ at FRF and $\alpha=4.5 \times 10^{-3}$ at MVCO, are relatively minor. For context, both of these values are in the middle of the range of bottom slopes at the mid-shelf sites examined by Lentz and Chapman (2004), which range from $1.5 \times 10^{-3}$ to $10^{-2}$. Although the continental shelf is relatively broad in the Mid-Atlantic Bight, both mooring arrays examined in this study are located over steeper nearshore bathymetry. Differences in $f$ of $8.6 \times 10^{-5} \mathrm{~s}^{-1}$ at FRF and $9.6 \times 10^{-5} \mathrm{~s}^{-1}$ at MVCO are also relatively minor. However, vertical shear and cross-shelf transport both differ substantially between the FRF and MVCO locations. Values of $\partial v / \partial z$ vary between $-2.1 \times 10^{-2}$ and $1.2 \times 10^{-2} \mathrm{~s}^{-1}$ at MVCO (Fig. 9) but vary over a much larger range from $-7.0 \times 10^{-2}$ to $7.0 \times 10^{-2} \mathrm{~s}^{-1}$ at FRF (Fig. 4c). Based on regression slopes between $f U_{s}$ and $\tau^{s y} / \rho_{0}$ during upwelling-favorable wind stress, the fraction of Ekman transport $U_{s} / U_{E k}$ is $0.20 \pm 0.08$ at the $6-8 \mathrm{~m}$ sites examined at FRF, and a much lower fraction 0.06 \pm 0.03 at the $7-12 \mathrm{~m}$ sites examined at MVCO despite their greater average depth (Fig. 
8a,c). Differences in the role of the nonlinear terms at FRF and MVCO are best explained by a combination of the strength of the cross-shelf circulation and the vertical shear in the alongshore flow. Stronger vertical mixing associated with stronger tidal currents may explain the lower fraction of Ekman transport (Castelao et al., 2010; e.g.) and weaker vertical shear over the New England inner shelf.

The bottom slope can be an important parameter because it helps determine the crossshelf scale of the momentum flux divergence. For example, the nonlinear momentum flux divergence has been found to play a major role in balancing the wind stress at sites onshore of Heceta Bank over the Oregon inner shelf (Kirincich and Barth, 2009b). This region has a relatively steep slope of $\alpha=0.0125$, steeper than the two locations examined in this study. Vertical shear estimated from a shipboard survey at this site gives $\partial v / \partial z \approx$ $1 \times 10^{-2} \mathrm{~s}^{-1}$ (Kirincich and Barth, 2009a), which is similar to the magnitude observed at MVCO (Fig. 10). At the $15 \mathrm{~m}$ isobath off Oregon, where $U_{s} / U_{E k} \approx 0.4$ (Kirincich et al., 2005), equation (15) gives an estimate of $\sim 0.67$ for the ratio of the nonlinear and wind stress terms. In contrast to this large influence of the nonlinear term over a steeply sloping inner shelf, the influence of the nonlinear term is expected to be much smaller at inner shelf locations with similar vertical shear but smaller bottom slopes. Over the west Florida inner shelf, $\partial v / \partial z$ can reach values of $\sim 2 \times 10^{-2} \mathrm{~s}^{-1}$ (Weisberg et al., 2001), but the bottom slope of $\alpha \approx 8 \times 10^{-4}$ is relatively small. In this case, equation (15) gives an upper bound of $\sim 0.33$ for the ratio of the nonlinear and wind stress terms at the boundary of the inner shelf and mid-shelf, consistent with a relatively minor role of the nonlinear terms in modeled alongshore momentum balances (Li and Weisberg, 1999; Weisberg et al., 2001). Similarly, the nonlinear momentum flux divergence is also expected to play a minor role over the New Jersey inner shelf, where $\alpha \approx 10^{-3}$ and $\partial v / \partial z$ reaches values of $\sim 1 \times 10^{-2}$ (Garvine, 2004). Although a moderate value of $S \approx 0.7$ over the New Jersey inner shelf suggests that nonlinear terms should be important based on the theory of Lentz and Chapman (2004), equation (15) gives an upper bound of $\sim 0.14$ for the ratio 
of the nonlinear and wind stress terms at the boundary of the inner shelf and mid-shelf. Garvine (2004) did not estimate the magnitude of the nonlinear term, but bottom stress was found to be substantial relative to the wind stress. Although the bottom slope plays an important role in determining the importance of nonlinear momentum fluxes over the inner shelf, dependence on the slope Burger number $S$ may not be always applicable in the same manner as mid-shelf sites in coastal upwelling regions.

The dynamical role of nonlinear momentum flux divergence is determined by a complex set of interactions between stratification, turbulent mixing, cross-shelf exchange and the alongshore flow, all of which are influenced by wind forcing. The nonlinear term reaches greater magnitudes when stratification values of $N>0.01 \mathrm{~s}^{-1}$ are present at MVCO (Fig. 10b). Stratification promotes cross-shelf exchange by reducing the boundary layer thickness and the turbulent stress at the base of the surface layer. Stratification can also promote the development of vertical shear by inhibiting shear instability. In addition to vertical density stratification, the cross-shelf density gradient has also been shown to influence mixing and exchange when the inner shelf is forced by cross-shelf wind stress (Horwitz and Lentz, 2014). The cross-shelf density gradient also influences vertical shear of the alongshore flow through thermal wind balance. Cross-shelf fluxes of alongshore momentum are therefore coupled with the cross-shelf advection of density. Cross-shelf fluxes of alongshore momentum can also influence mixing by reducing the role of bottom friction on the inner shelf, which can then promote near-bottom stratification in a positive feedback mechanism.

A limitation of this study is that that it does not account for the three dimensional aspects of the inner shelf circulation. Alongshore pressure gradients are an important component of the alongshore momentum balances at FRF and MVCO (Lentz et al., 1999; Fewings and Lentz, 2010), but observational estimates are not available concurrent with the observations presented in this study. At FRF, the alongshore pressure gradient is uncorrelated with the alongshore wind stress and is driven in part by Chesapeake Bay plume 
events (Lentz et al., 1999). The low salinity signature of the plume is evident in Fig. 4f and the unresolved pressure gradient contributes to unresolved variance in the momentum balance analysis. In contrast, at MVCO, the alongshore pressure gradient largely balances the local wind stress, likely due to the effects of topography (Fewings and Lentz, 2010). Inclusion of an alongshore pressure gradient in the theory of Lentz and Chapman (2004) does not alter the dependence of the nonlinear term on the slope Burger number over the mid-outer shelf. Similarly, even if there is a substantial alongshore pressure gradient over the inner shelf, it cannot completely balance the wind stress if there is a cross-shelf momentum flux divergence associated with cross-shelf circulation and vertically-sheared alongshore flow.

Alongshore variations in velocity associated with three dimensional circulation patterns, which are neglected in the simplified momentum balance in equation (3), may also be significant. High-frequency radar observations of the surface circulation at MVCO suggest that momentum fluxes associated with lateral exchange can be important near complex bathymetry (Kirincich et al., 2013). Three dimensional processes may also affect the nonlinear momentum fluxes associated with two-dimensional upwelling and downwelling circulation patterns, which are the primary focus of this study. For example, Kumar and Feddersen (2017) show that including transient rip currents in a numerical model of circulation over a stratified inner shelf causes thermal wind balance to break down. Transient rip currents over the inner shelf may therefore influence the vertical shear of the alongshore flow, modulating the cross-shelf flux of alongshore momentum associated with upwelling and downwelling. Submesoscale fronts over the inner shelf may be associated with alongshore convergence, as well as alongshore variations in vertical shear $\partial v / \partial z$ (Dauhajre et al., 2017; Wu et al., 2021). Because nonlinear processes can significantly influence the alongshore momentum balance, studies of inner shelf dynamics should consider the potential for coupling between the dynamics of wind-driven circulation, submesoscale features and wave-driven flow over the inner shelf. 
An implication of this study is that the cross-shelf wind stress can play a role in the alongshore momentum balance. The cross-shelf wind stress increases surface transport $U_{s}$ in shallow water, where alongshore wind stress is inefficient at driving cross-shelf exchange (Tilburg, 2003; Fewings et al., 2008). Increased surface transport increases the magnitude of the nonlinear momentum flux divergence relative to the wind stress in the scaling of the two terms in equation (15). However, cross-shelf wind stress alone does not drive significant alongshore flow (Tilburg, 2003), and therefore would not be expected to produce a strong momentum flux divergence. Combined offshore and upwelling-favorable wind stress, typical for the FRF site examined in this study, may provide optimal conditions for an important role of the nonlinear momentum flux divergence over the inner shelf.

\section{Conclusion}

The results of this study show that cross-shelf fluxes of alongshore momentum influence the physical dynamics of the inner shelf. The two locations examined contrast strongly in the circulation patterns associated with nonlinear momentum fluxes, and their overall importance in the alongshore momentum balance. Over the North Carolina inner shelf, the momentum flux divergence plays an important role in balancing the alongshore wind stress during upwelling-favorable and offshore winds. During reversals to downwelling-favorable and onshore forcing, the momentum flux divergence acts in the same direction as the wind stress, allowing bottom stress to exceed the wind stress. Over the New England inner shelf, the importance of the momentum flux divergence is reduced, and tends to act in opposition to both upwelling-favorable and downwelling-favorable wind stress. These differences over the New England inner shelf are consistent with a combination of weaker stratification, weaker vertical shear, a background mean upwelling circulation, and cross-shelf wind stress that tends counteract the surface transport driven by alongshore wind stress. 
The role of the nonlinear momentum flux divergence should be taken into account at inner shelf locations characterized by strong vertical shear and steep bottom slope. The mechanism described in this study is similar to that described by Lentz and Chapman (2004) for mid-shelf sites. However, the relationship between wind forcing, stratification, the cross-shelf density gradient, turbulent mixing and vertical shear is complex over the inner shelf. This complexity is not captured by a simple dependence on the slope Burger number. In addition, because cross-shelf winds influence transport in the surface layer, the cross-shelf component of wind stress has the potential to influence the alongshore momentum balance over the inner shelf. The dynamics of the shallow inner shelf are often characterized by an overall balance between wind stress and bottom stress. However, nonlinear momentum fluxes can either reduce or increase the role of bottom stress relative to the wind stress, which affects the relationship between mixing and exchange over the inner shelf.

Acknowledgments. We are grateful to all of the scientists, engineers and technicians at Woods Hole Oceanographic Institution and the Army Corps of Engineers Field Research Facility who contributed to the collection of time series data analyzed in this study. This analysis would not have been possible without the great effort involved in collecting highquality observations over multiple years. Current meter and water property data from the North Carolina inner shelf are publicly available at http://www.frf.usace.army.mil. Data are provided by the Field Research Facility, Coastal Observations \& Analysis Branch, US Army Corps of Engineers, Duck, North Carolina. Current meter and water property data from the New England inner shelf are publicly available from the Woods Hole Open Access Server (Lentz, 2021). Support for this work was provided by the National Science Foundation (OCE-1433716 and OCE-1558874). We thank the two reviewers for their helpful feedback. 
Austin, J. A. 1999. The role of the alongshore wind stress in the heat budget of the North Carolina inner shelf. J. Geophys. Res. Ocean., 104(C8), 18187-18203. doi: 10.1029/1998JC900122.

Austin, J. A. and S. J. Lentz. 1999. The relationship between synoptic weather systems and meteorological forcing on the North Carolina inner shelf. J. Geophys. Res. Ocean., 104(C8), 159-185. doi: 10.1029/1999JC900016.

Austin, J. A. and S. J. Lentz. 2002. The inner shelf response to wind-driven upwelling and downwelling. J. Phys. Ocean., 32, 2171-2193.

Castelao, R., R. Chant, S. Glenn, and O. Schofield. 2010. The effects of tides and oscillatory winds on the subtidal inner-shelf cross-shelf circulation. J. Phys. Oceanogr., 40 (4), 775-788. doi: 10.1175/2009JPO4273.1.

Chen, S.-Y. and S.-N. Chen. 2017. Generation of upwelling circulation under downwelling-favorable wind within bottom-attached, buoyant coastal currents. J. Phys. Oceanogr., 47(10), 2499-2519. doi: 10.1175/JPO-D-16-0271.1.

Codiga, D. 2011. Unified tidal analysis and prediction using the UTide Matlab functions. Technical report, Graduate School of Oceanography, University of Rhode Island, Narragansett, RI. URL http://www.po.gso.uri.edu/ codiga/utide/utide.htm.

Cudaback, C. N. and J. L. Largier. 2001. The cross-shelf structure of wind- and buoyancydriven circulation over the North Carolina inner shelf. Cont. Shelf Res., 21(15), 16491668. doi: 10.1016/S0278-4343(01)00025-5.

Dauhajre, D. P., J. C. McWilliams, and Y. Uchiyama. 2017. Submesoscale coherent structures on the continental shelf. J. Phys. Oceanogr., 47(12), 2949-2976. doi: 10.1175/JPO-D-16-0270.1. 
Feddersen, F., R. T. Guza, S. Elgar, and T. H. C. Herbers. 1998. Alongshore momentum balances in the nearshore. J. Geophys. Res. Ocean., 103(C8), 15667-15676. doi: 10.1029/98JC01270.

Fewings, M., S. J. Lentz, and J. Fredericks. 2008. Observations of cross-shelf flow driven by cross-shelf winds on the inner continental shelf. J. Phys. Oceanogr., 38, 2358-2378.

Fewings, M. R. and S. J. Lentz. 2010. Momentum balances on the inner continental shelf at Martha's Vineyard Coastal Observatory. J. Geophys. Res. Ocean., 115(12), C12023. doi: 10.1029/2009JC005578.

Fewings, M. R. and S. J. Lentz. 2011. Summertime cooling of the shallow continental shelf. J. Geophys. Res. Ocean., 116(C7). doi: 10.1029/2010JC006744.

Ganju, N. K., S. J. Lentz, A. R. Kirincich, and J. T. Farrar. 2011. Complex mean circulation over the inner shelf south of Martha's Vineyard revealed by observations and a high-resolution model. J. Geophys. Res., 116, C10036. doi: 10.1029/2011JC007035.

Garvine, R. W. 2004. The vertical structure and subtidal dynamics of the inner shelf off New Jersey. J. Mar. Res., 62(3), 337-371. doi: 10.1357/0022240041446182.

Grifoll, M., A. L. Aretxabaleta, M. Espino, and J. C. Warner. 2012. Along-shelf current variability on the Catalan inner-shelf (NW Mediterranean). J. Geophys. Res. Ocean., 117(C9). doi: 10.1029/2012JC008182.

Hickey, B. M. 1989. Patterns and processes of circulation over the Washington continental shelf and slope. In Landry, M. R. and B. M. Hickey, editors, Coastal Oceanography of Washington and Oregon, pages 41-115. Elsevier.

Horwitz, R. and S. J. Lentz. 2014. Inner-shelf response to cross-shelf wind stress: The importance of the cross-shelf density gradient in an idealized numerical model and field observations. J. Phys. Oceanogr., 44(1), 86-103. doi: 10.1175/JPO-D-13-075.1. 
Horwitz, R. M. and S. J. Lentz. 2016. The effect of wind direction on cross-shelf transport on an initially stratified inner shelf. J. Mar. Res., 74, 201-227. doi: $10.1357 / 002224016820870648$.

Kirincich, A. R. 2013. Long-term observations of turbulent Reynolds stresses over the inner continental shelf. J. Phys. Oceanogr., 43(12), 2752-2771. doi: 10.1175/JPO-D12-0153.1.

Kirincich, A. R. and J. A. Barth. 2009a. Time-varying across-shelf Ekman transport and vertical eddy viscosity on the inner shelf. J. Phys. Oceanogr., 39, 602-620.

Kirincich, A. R. and J. A. Barth. 2009b. Alongshelf variability of inner-shelf circulation along the central Oregon coast during summer. J. Phys. Oceanogr., 39(6), 1380-1398. doi: $10.1175 / 2008 J P O 3760.1$.

Kirincich, A. R., J. A. Barth, B. A. Grantham, B. A. Menge, and J. Lubchenco. 2005. Wind-driven inner-shelf circulation off central Oregon during summer. J. Geophys. Res., 110(10), C10S03. doi: 10.1029/2004JC002611.

Kirincich, A. R., S. J. Lentz, J. T. Farrar, and N. K. Ganju. 2013. The spatial structure of tidal and mean circulation over the inner shelf south of Martha's Vineyard, Massachusetts. J. Phys. Oceanogr., 43(9), 1940-1958. doi: 10.1175/JPO-D-13-020.1.

Kuebel Cervantes, B. T., J. S. Allen, and R. M. Samelson. 2003. A modeling study of Eulerian and Lagrangian aspects of shelf circulation off Duck, North Carolina. J. Phys. Oceanogr., 33(10), 2070-2092.

Kuebel Cervantes, B. T., J. S. Allen, and R. M. Samelson. 2004. Lagrangian characteristics of continental shelf flows forced by periodic wind stress. Nonlinear Process. Geophys., 11(1), 3-16. doi: 10.5194/npg-11-3-2004. 
Kumar, N. and F. Feddersen. 2017. The effect of Stokes drift and transient rip currents on the inner shelf. Part II: With stratification. J. Phys. Oceanogr., 47(1), 243-260. doi: 10.1175/JPO-D-16-0077.1.

Lee, G.-h., C. T. Friedrichs, and C. E. Vincent. 2002. Examination of diffusion versus advection dominated sediment suspension on the inner shelf under storm and swell conditions, Duck, North Carolina. J. Geophys. Res., 107(C7), 3084. doi: $10.1029 / 2001 J C 000918$.

Lentz, S. J. 1995. Sensitivity of the inner-shelf circulation to the form of the eddy viscosity profile. J. Phys. Oceanogr., 25, 19-28.

Lentz, S. J. 2001. The influence of stratification on the wind-driven cross-shelf circulation over the North Carolina shelf. J. Phys. Oceanogr., 31(9), 2749-2760. doi: 10.1175/1520-0485(2001)031;2749:TIOSOT ¿2.0.CO;2.

Lentz, S. J. 2008a. Seasonal variations in the circulation over the Middle Atlantic Bight continental shelf. J. Phys. Oceanogr., 38, 1486-1500. doi: 10.1175/2007JPO3767.1.

Lentz, S. J. 2008b. Observations and a model of the mean circulation over the Middle Atlantic Bight continental shelf. J. Phys. Oceanogr., 38, 1203-1221. doi: 10.1175/2007JPO3768.1.

Lentz, S. J. 2021. Dataset: Stratification, Wind, and Waves on the Inner shelf of Martha's Vineyard (SWWIM). WHOAS: Woods Hole Open Access Server. Last modified 8 June 2021. doi: 10.26025/1912/27252. URL https://hdl.handle.net/1912/27252.

Lentz, S. J. and D. C. Chapman. 2004. The importance of the nonlinear cross-shelf momentum flux during wind-driven coastal upwelling. J. Phys. Oceanogr., 34(11), 2444-2457. 
Lentz, S. J. and M. R. Fewings. 2012. The wind- and wave-driven inner-shelf circulation. Ann. Rev. Mar. Sci., 4, 317-343. doi: 10.1146/annurev-marine-120709-142745.

Lentz, S. J., M. Fewings, P. Howd, J. Fredericks, and K. Hathaway. 2008. Observations and a model of undertow over the inner continental shelf. J. Phys. Oceanogr., 38(11), 2341-2357. doi: 10.1175/2008JPO3986.1.

Lentz, S., R. T. Guza, S. Elgar, F. Feddersen, and T. H. C. Herbers. 1999. Momentum balances on the North Carolina inner shelf. J. Geophys. Res. Ocean., 104(C8), 1820518226. doi: 10.1029/1999JC900101.

Lentz, S. J. and J. Largier. 2006. The influence of wind forcing on the Chesapeake Bay buoyant coastal current. J. Phys. Oceanogr., 36(2005), 1305-1316. doi: 10.1175/JPO2909.1.

Li, Z. and R. H. Weisberg. 1999. West Florida continental shelf response to upwelling favorable wind forcing 2. Dynamics. J. Geophys. Res., 104(C10), 23427-23442.

Liu, Y. and R. H. Weisberg. 2005. Momentum balance diagnoses for the West Florida Shelf. Cont. Shelf Res., 25(17), 2054-2074. doi: 10.1016/j.csr.2005.03.004.

Mazzini, P. L., R. J. Chant, M. E. Scully, J. Wilkin, E. J. Hunter, and N. J. Nidzieko. 2019. The impact of wind forcing on the thermal wind shear of a river plume. J. Geophys. Res. Ocean., 124(11), 7908-7925. doi: 10.1029/2019JC015259.

Mitchum, G. T. and A. J. Clarke. 1986. The frictional nearshore response to forcing by synoptic scale winds. J. Phys. Oceanogr., 16(5), 934-946.

Monismith, S. G. and D. A. Fong. 2004. A note on the potential transport of scalars and organisms by surface waves. Limnol. Oceanogr., 49(4), 1214-1217. doi: 10.4319/1o.2004.49.4.1214. 
Moody, J. A., B. Butman, R. C. Beardsley, W. S. Brown, P. Daifuku, J. D. Irish, D. A. Mayer, H. O. Mofjeld, B. Petrie, S. Ramp, P. Smith, and W. R. Wright. 1984. Atlas of tidal elevation and current observations on the Northeast American continental shelf and slope. Bulletin 1611. Technical report, U.S. Geological Survey. URL http://pubs.er.usgs.gov/publication/b1611.

Ofsthun, C., X. Wu, G. Voulgaris, and J. C. Warner. 2019. Alongshore momentum balance over shoreface-connected ridges, Fire Island, NY,. Cont. Shelf Res., 186, 21-33. doi: 10.1016/j.csr.2019.07.005.

Rennie, S. E., J. L. Largier, and S. J. Lentz. 1999. Observations of a pulsed buoyancy current downstream of Chesapeake Bay. J. Geophys. Res., 104(C8), 18227. doi: 10.1029/1999JC900153.

Rosenfeld, L. K. 1983. CODE-1: Moored array and large-scale data report, Technical Report 83-23, Woods Hole Oceanographic Institution. Technical report, Woods Hole Oceanographic Institution.

Smith, J. A. 2006. Wave-current interactions in finite depth. J. Phys. Oceanogr., 36(7), 1403-1419. doi: 10.1175/JPO2911.1.

Smith, S. D. 1988. Coefficients for sea surface wind stress, heat flux, and wind profiles as a function of wind speed and temperature. J. Geophys. Res. Ocean., 93(C12), 1546715472. doi: 10.1029/JC093iC12p15467.

Thieler, E., D. Foster, D. Mallinson, E. Himmelstoss, J. McNinch, J. List, and E. HammarKlose. 2013. Quaternary geophysical framework of the northeastern North Carolina coastal system: U.S. Geological Survey Open-File Report 2011-2015. URL https://pubs.usgs.gov/of/2011/1015/.

Tilburg, C. E. 2003. Across-shelf transport on a continental shelf: Do across-shelf winds matter? J. Phys. Oceanogr., 33(12), 2675-2688. 
Uchiyama, Y., J. C. McWilliams, and A. F. Shchepetkin. 2010. Wave-current interaction in an oceanic circulation model with a vortex-force formalism: Application to the surf zone. Ocean Model., 34, 16-35. doi: 10.1016/j.ocemod.2010.04.002.

Weisberg, R. H., Z. Li, and F. Muller-Karger. 2001. West Florida shelf response to local wind forcing: April 1998. J. Geophys. Res. Ocean., 106(C12), 31239-31262. doi: 10.1029/2000JC000529.

Woodson, C. B. 2013. Spatiotemporal variation in cross-shelf exchange across the inner shelf of Monterey Bay, California. J. Phys. Oceanogr., 43(8), 1648-1665. doi: 10.1175/JPO-D-11-0185.1.

Wu, X., F. Feddersen, and S. N. Giddings. 2021. Characteristics and dynamics of density fronts over the inner to midshelf under weak wind conditions. J. Phys. Oceanogr., 51 (3), 789-808. doi: 10.1175/JPO-D-20-0162.1.

Xu, F.-H. and L.-Y. Oey. 2011. The origin of along-shelf pressure gradient in the Middle Atlantic Bight. J. Phys. Oceanogr., 41(9), 1720-1740. doi: 10.1175/2011JPO4589.1.

Xu, Z. and A. J. Bowen. 1994. Wave- and wind-driven flow in water of finite depth. J. Phys. Oceanogr., 24, 1850-1866. 
Table 1: Results from piecewise linear regressions between wind stress and nonlinear terms in the depth averaged momentum balance over the North Carolina inner shelf during June-August. Analysis is restricted to time periods when each site is outside the surf zone and $\bar{u}_{L}<0.03 \mathrm{~m} / \mathrm{s}$. Regression slopes are given with $95 \%$ confidence intervals for both upwelling favorable wind stress (positive $\tau^{s y}$ ) and downwelling favorable wind stress (negative $\tau^{s y}$ ) at five different pairs of sites. Results from the $6 \mathrm{~m}-8 \mathrm{~m}$ sites are shown in Figure 6.

\begin{tabular}{rcc}
\hline \hline Sites & Upwelling favorable & Downwelling favorable \\
\hline $5 \mathrm{~m}-6 \mathrm{~m}$ & $0.51 \pm 0.5$ & $-0.15 \pm 0.6$ \\
$5 \mathrm{~m}-8 \mathrm{~m}$ & $0.5 \pm 0.21$ & $-0.38 \pm 0.22$ \\
$6 \mathrm{~m}-8 \mathrm{~m}$ & $0.57 \pm 0.21$ & $-0.77 \pm 0.51$ \\
$6 \mathrm{~m}-11 \mathrm{~m}$ & $0.87 \pm 0.32$ & $-0.46 \pm 0.36$ \\
$8 \mathrm{~m}-11 \mathrm{~m}$ & $0.66 \pm 0.4$ & $-0.32 \pm 0.33$ \\
\hline
\end{tabular}


1206

1207

1208

1209

1210

1211

1212

1213

1214

1215

1216

1217

1218

1219

1220

1221

\section{List of Figures}

1 a) Coastline and bathymetry of the Mid-Atlantic Bight region. Red squares indicate locations of long-term current meter arrays used in this study. Red triangle indicates location of long-term tide gauge at the mouth of Chesapeake Bay. Gray contours indicate isobaths at $20-\mathrm{m}$ intervals out to 200 m. b) Overview of FRF field site at Duck, NC, showing locations of current meters (circles), tide gauge (triangle) and meteorological observations (square). Contours indicate isobaths at $2 \mathrm{~m}$ intervals, starting at the $4 \mathrm{~m}$ isobath. Axes show average offshore $(x)$ and upwelling-favorable $(y)$ coordinate system orientation determined from principal axis analyses of current meter data. Length of arrows depicts horizontal scale of $300 \mathrm{~m}$. c) Overview of MVCO field site at Martha's Vineyard, MA, showing locations of current meters at the $7 \mathrm{~m}$ and $12 \mathrm{~m}$ isobaths from the SWWIM project (circles) and MVCO beach meteorological observations (square). Contours indicate isobaths at $2 \mathrm{~m}$ intervals, starting at the $2 \mathrm{~m}$ isobath. Coordinate system and scales as in panel b. . . . . . . . . . . 55 
2 Comparison of stratification $(a, b)$ and wind stress $(c, d)$ at the FRF site in Duck, NC (left column) and Martha's Vineyard, MA (right column). a) Monthly averages of buoyancy frequency, $N$, calculated from daily vertical profiles at the end of the FRF pier (black circles). Line shows seasonal climatology computed from monthly averages. b) Monthly averages and seasonal climatology of $N$ computed from all SWWIM mooring observations at the $7 \mathrm{~m}$ site (gray circles and solid line) and $12 \mathrm{~m}$ site (black circles and solid line). Monthly averages and climatology of $N$ computed from daily maxima at the $7 \mathrm{~m}$ site are also shown (gray triangles and dashed line). c) Wind rose plot for FRF site, showing frequency of occurrence of wind stress magnitude $\left(\mathrm{N} / \mathrm{m}^{2}\right)$ and direction at FRF site during the months of June-August. The coordinate system has been rotated relative to offshore $(x)$ and upwelling-favorable $(y)$ coordinates shown in Figure 1b. d) As in panel c, for MVCO site and coordinate system shown in Figure 1c. . 56

3 Cross-shelf and along-shelf components of wind stress $\left(\tau^{s x}, \tau^{s y}\right)$ during the months of June-August, with colors indicating surface transport $U_{s}$ at a) FRF, and b) MVCO. Each point represents a 33-hour average of lowpass filtered data. . . . . . . . . . . . . . . 57 
4 Time series at FRF during the 45-day period 13 June-28 July 2013. a) Cross-shore (red) and alongshore (blue) components of wind stress. b) Cross-shore surface transport, $U_{S}$, at the $8 \mathrm{~m}$ (black), $6 \mathrm{~m}$ (dark gray) and $5 \mathrm{~m}$ (light gray) sites. c) Vertical shear in alongshore currents, $\partial v / \partial z$, at the $6 \mathrm{~m}$ and $8 \mathrm{~m}$ sites. d) Selected terms in the depth-integrated alongshore momentum balance, averaged between the $6 \mathrm{~m}$ and $8 \mathrm{~m}$ sites: wind stress $\left(\tau^{s y} / \rho_{o} D\right.$, blue $)$ and nonlinear advection $\left(1 / D \partial / \partial x \int_{-h}^{\eta}\left(u_{L} v\right) d z\right.$, red). e) Selected terms in the depth-integrated alongshore momentum balance, averaged between the $6 \mathrm{~m}$ and $8 \mathrm{~m}$ sites: wind stress $\left(\tau^{s y} / \rho_{o} D\right.$, blue $)$ and logarithmic bottom stress ( $\tau^{b y} / \rho_{o} D$, black). f) Practical salinity, $S_{P}$, from CTD casts at a depth of $1 \mathrm{~m} . \ldots \ldots . \ldots . \ldots 58$

5 Comparison of wind stress, bottom stress and nonlinear advection terms in the depth-averaged alongshore momentum balance at FRF during JuneAugust. Wind stress term vs. bottom stress (BS) term (blue); wind stress term vs. sum of bottom stress and nonlinear (BS + NL) terms (red); and wind stress term vs. sum of bottom stress, nonlinear and acceleration (BS $+\mathrm{NL}+\mathrm{A}$ ) terms (black). Each circle represents a 33-hour average of lowpass filtered data. Squares are bin averages, with vertical lines showing standard errors. . . . . . . . . . . . . . . . . . . 59

6 Comparison of wind stress and nonlinear advection terms in the alongshore momentum balance during June-August. a) At FRF over the North Carolina inner shelf. Red lines indicate results of piecewise linear regressions of the 33-hour subsampled values, one regression for positive values of wind stress and another for negative values of wind stress. b) At MVCO over the New England inner shelf. One linear regression is used for both positive and negative values of wind stress. Note difference in scale between panels a and $b . \ldots \ldots \ldots \ldots$ 
1267 7 Comparison of variability in the nonlinear and wind stress terms in the alongshore momentum balance. a). Ratio of standard deviations of the nonlinear term and wind stress term at FRF over the North Carolina inner shelf. Black bars show ratios during June-August and gray bars show ratios during January-February. Ratios are shown for five different pairs of sites. Vertical lines indicate $95 \%$ confidence intervals. b) As in panel a, for three pairs of sites at MVCO over the New England inner shelf. . . . . 60

8 Comparison of wind stress, Coriolis and nonlinear advection terms in the surface layer-integrated alongshore momentum balance at FRF during June-August. a) Wind stress term vs. Coriolis terms at FRF. Each circle indicates a 33-hour average of low-pass filtered data. Lines indicate separate linear regression fits for positive and negative wind stress values. Regression slopes are shown with $95 \%$ confidence intervals. b) As in panel a, for wind stress term vs. nonlinear terms at FRF. c) As in panel a, for wind stress term vs. Coriolis term at MVCO. d) As in panel a, for wind stress term vs. nonlinear terms at $\mathrm{MVCO}$, and with one linear regression fit for all data points. . . . . . . . . . . . . . . 61

9 Evaluation of processes governing vertical shear, $\partial v / \partial z$, at MVCO. a) Hypothetical vertical shear associated with thermal wind balance in equation (8). Circles indicate relatively strong stratification, $N>0.01$. Triangles indicate relatively weak stratification, $N \leq 0.01$. Black dashed line indicates 1:1 relationship. b) Hypothetical vertical shear associated with alongshore wind stress $\tau^{s y}$ and eddy viscosity $A=\kappa u_{*} h / 6$ in equation (9). 62 
10 a) Wind stress term $\tau^{s y} /\left(\rho_{o} h\right)$ vs. the thermal wind balance residual $\partial v / \partial z+g /\left(f \rho_{o}\right) \partial \rho / \partial x$ at MVCO. Circles indicate relatively strong stratification, $N>0.01$. Triangles indicate relatively weak stratification, $N \leq 0.01$. b) Wind stress and nonlinear advection terms in the depthaveraged momentum balance at MVCO under different levels of stratifi-

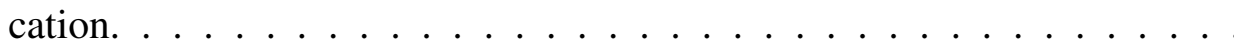

11 Conceptual models of circulation patterns associated with nonlinear momentum fluxes at different locations and under different forcing conditions. Arrows represent cross-shelf and vertical vector components. Circles represent alongshore vector components $(\otimes$ indicates wind stress or ocean velocity in the positive $y$ direction). Dashed lines indicate isopycnals, where darker shading is relatively dense. a) FRF, upwelling-favorable and offshore wind stress. b) FRF, downwelling-favorable and onshore wind stress. c) MVCO, upwelling-favorable and onshore wind stress. d) MVCO, downwelling-favorable and offshore wind stress. . . . . . .

12 Standard deviations of the depth-integrated nonlinear momentum flux as a function of water depth, for the months of June-August. Black symbols represent estimates from FRF and gray symbols represent estimates from MVCO. Vertical bars indicate $95 \%$ confidence intervals. Dashed lines show hypothetical dependence on $a h^{2}$, where $a$ is a constant coefficient obtained from a least squares fit at each location. . . . . . . . . . 65 
13 Simplified representations of the nonlinear term in the depth-averaged mo1312 mentum balance. a) Comparison of the approximation in equation (10) 1313 estimated from single deeper mooring ( $x$-axis) vs. full estimate from 1314 mooring pairs ( $y$-axis). Black symbols represent estimates from the 6-8m sites at FRF and gray symbols represent estimates from the $7-12 \mathrm{~m}$ sites at MVCO. Blacked dashed line represents 1:1 agreement. b) Comparison of the scaling in equation (13) estimated from single deeper mooring ( $x$-axis) vs. full estimate from mooring pairs ( $y$-axis). Symbols as in panel a. . . . 

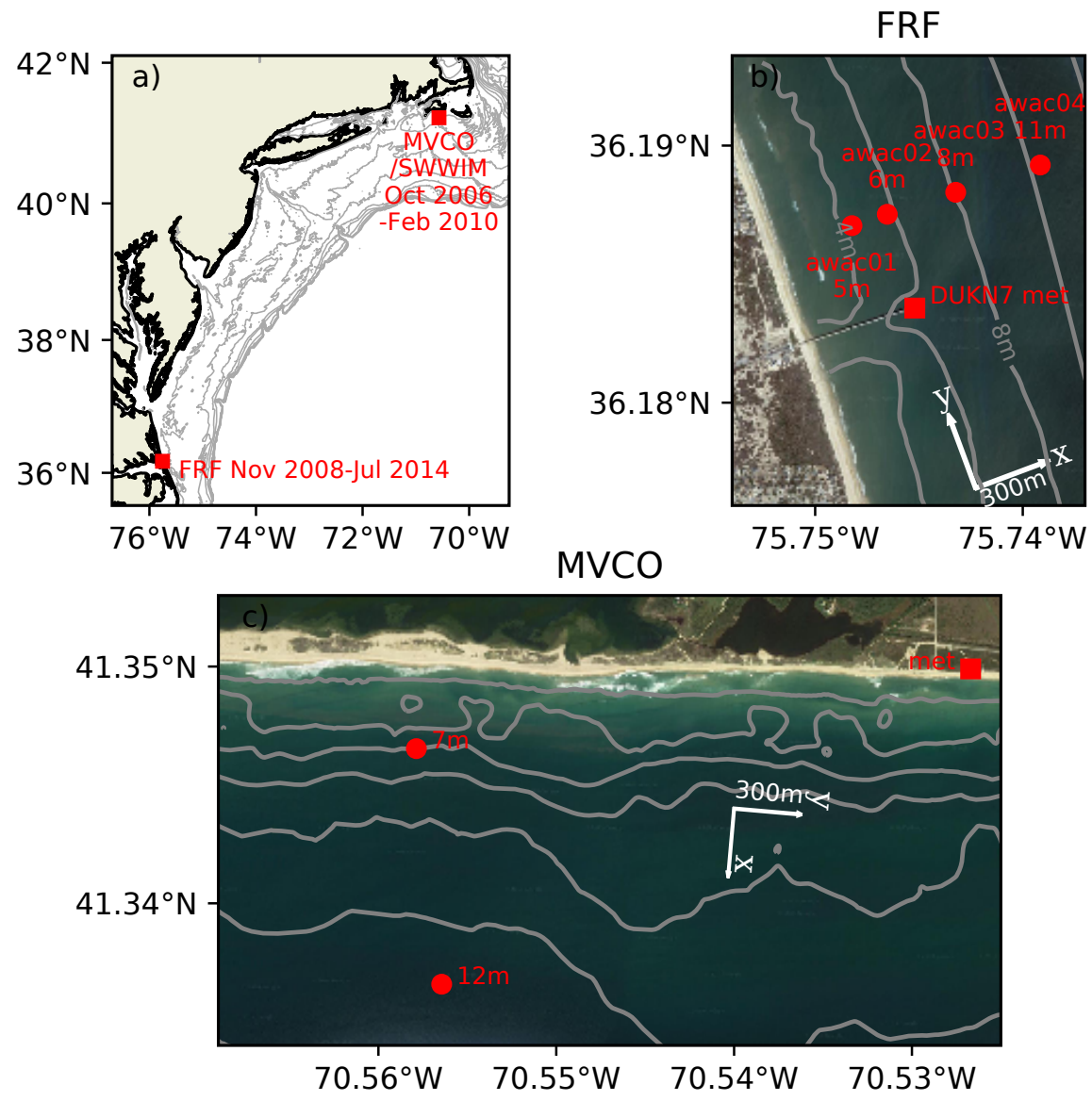

Figure 1: a) Coastline and bathymetry of the Mid-Atlantic Bight region. Red squares indicate locations of long-term current meter arrays used in this study. Red triangle indicates location of long-term tide gauge at the mouth of Chesapeake Bay. Gray contours indicate isobaths at 20-m intervals out to $200 \mathrm{~m}$. b) Overview of FRF field site at Duck, $\mathrm{NC}$, showing locations of current meters (circles), tide gauge (triangle) and meteorological observations (square). Contours indicate isobaths at $2 \mathrm{~m}$ intervals, starting at the 4 $\mathrm{m}$ isobath. Axes show average offshore $(x)$ and upwelling-favorable $(y)$ coordinate system orientation determined from principal axis analyses of current meter data. Length of arrows depicts horizontal scale of $300 \mathrm{~m}$. c) Overview of MVCO field site at Martha's Vineyard, MA, showing locations of current meters at the $7 \mathrm{~m}$ and $12 \mathrm{~m}$ isobaths from the SWWIM project (circles) and MVCO beach meteorological observations (square). Contours indicate isobaths at $2 \mathrm{~m}$ intervals, starting at the $2 \mathrm{~m}$ isobath. Coordinate system and scales as in panel $b$. 

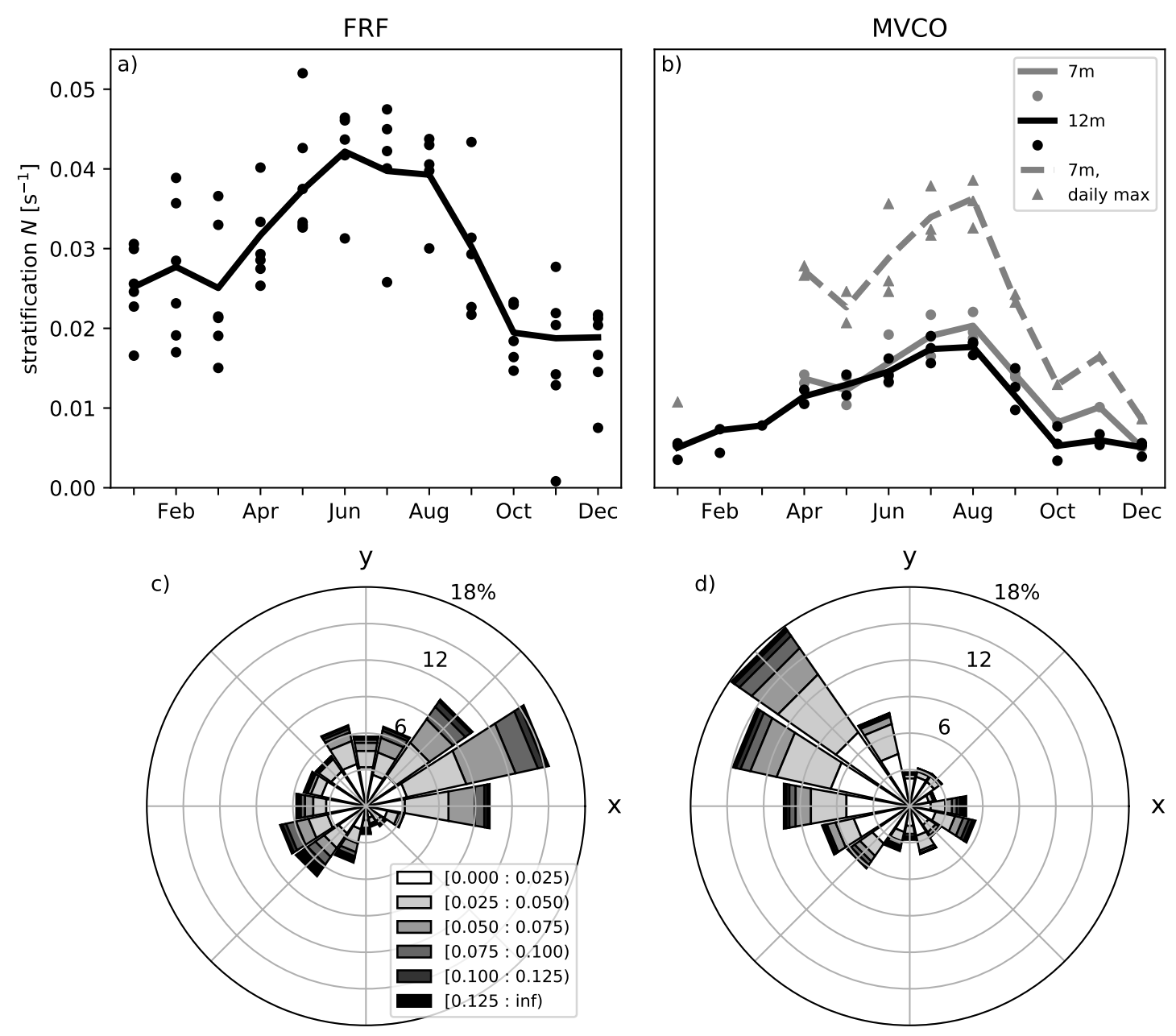

Figure 2: Comparison of stratification $(a, b)$ and wind stress $(c, d)$ at the FRF site in Duck, NC (left column) and Martha's Vineyard, MA (right column). a) Monthly averages of buoyancy frequency, $N$, calculated from daily vertical profiles at the end of the FRF pier (black circles). Line shows seasonal climatology computed from monthly averages. b) Monthly averages and seasonal climatology of $N$ computed from all SWWIM mooring observations at the $7 \mathrm{~m}$ site (gray circles and solid line) and $12 \mathrm{~m}$ site (black circles and solid line). Monthly averages and climatology of $N$ computed from daily maxima at the $7 \mathrm{~m}$ site are also shown (gray triangles and dashed line). c) Wind rose plot for FRF site, showing frequency of occurrence of wind stress magnitude $\left(\mathrm{N} / \mathrm{m}^{2}\right)$ and direction at FRF site during the months of June-August. The coordinate system has been rotated relative to offshore $(x)$ and upwelling-favorable $(y)$ coordinates shown in Figure 1b. d) As in panel c, for MVCO site and coordinate system shown in Figure 1c. 

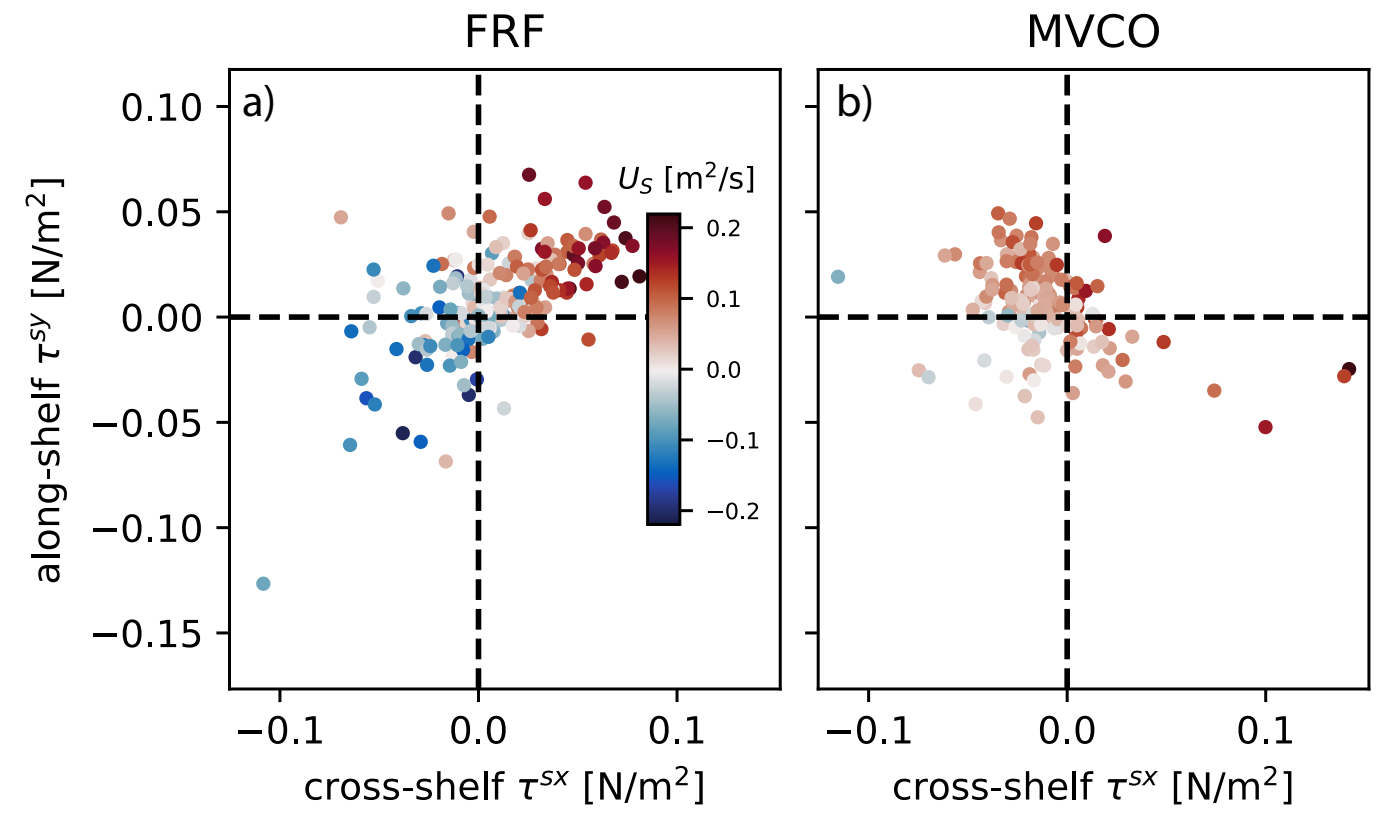

Figure 3: Cross-shelf and along-shelf components of wind stress $\left(\tau^{s x}, \tau^{s y}\right)$ during the months of June-August, with colors indicating surface transport $U_{s}$ at a) FRF, and b) MVCO. Each point represents a 33-hour average of low-pass filtered data. 

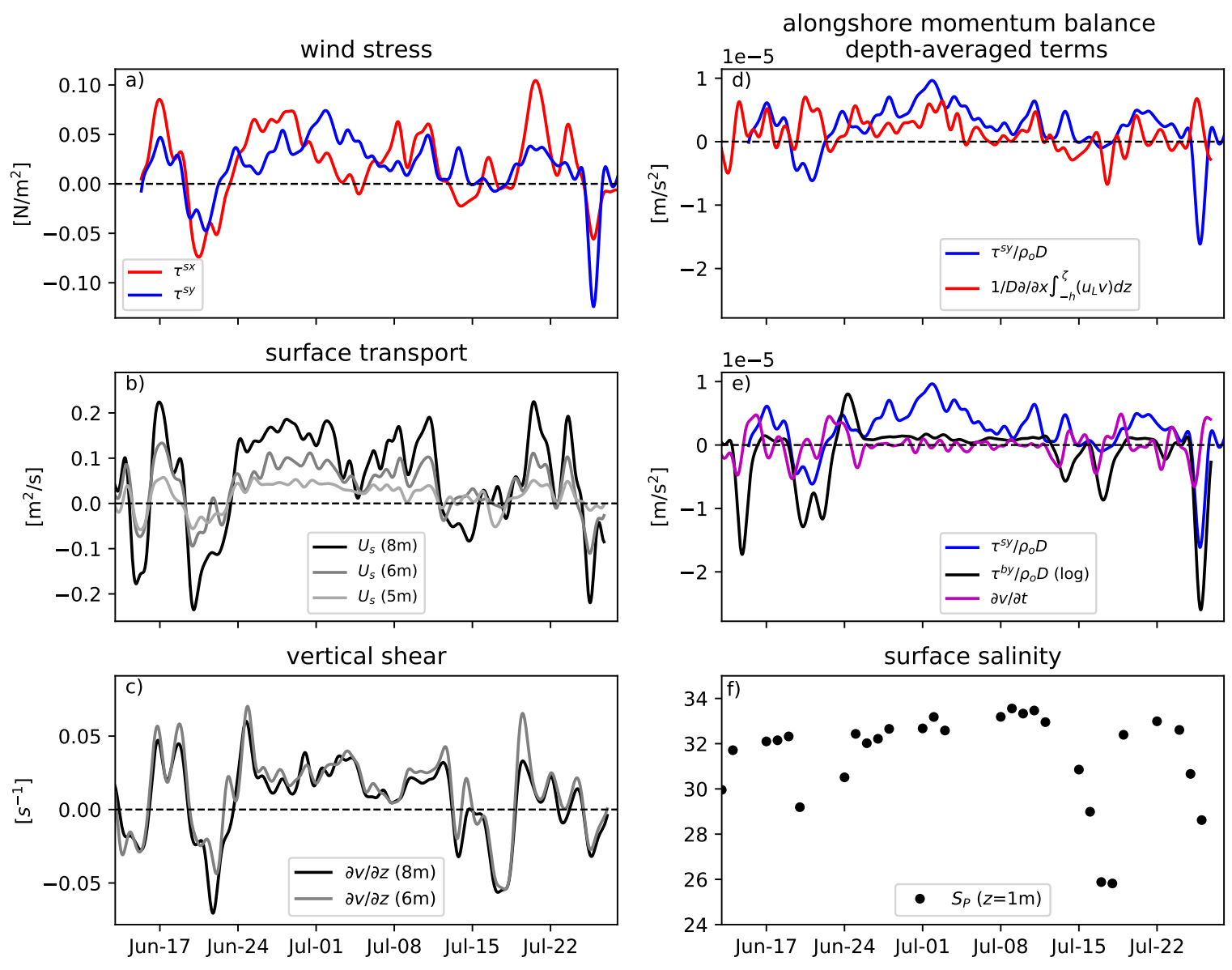

Figure 4: Time series at FRF during the 45-day period 13 June-28 July 2013. a) Crossshore (red) and alongshore (blue) components of wind stress. b) Cross-shore surface transport, $U_{S}$, at the $8 \mathrm{~m}$ (black), $6 \mathrm{~m}$ (dark gray) and $5 \mathrm{~m}$ (light gray) sites. c) Vertical shear in alongshore currents, $\partial v / \partial z$, at the $6 \mathrm{~m}$ and $8 \mathrm{~m}$ sites. d) Selected terms in the depthintegrated alongshore momentum balance, averaged between the $6 \mathrm{~m}$ and $8 \mathrm{~m}$ sites: wind stress $\left(\tau^{s y} / \rho_{o} D\right.$, blue) and nonlinear advection $\left(1 / D \partial / \partial x \int_{-h}^{\eta}\left(u_{L} v\right) d z\right.$, red). e) Selected terms in the depth-integrated alongshore momentum balance, averaged between the $6 \mathrm{~m}$ and $8 \mathrm{~m}$ sites: wind stress $\left(\tau^{s y} / \rho_{o} D\right.$, blue $)$ and logarithmic bottom stress $\left(\tau^{b y} / \rho_{o} D\right.$, black). f) Practical salinity, $S_{P}$, from CTD casts at a depth of $1 \mathrm{~m}$. 


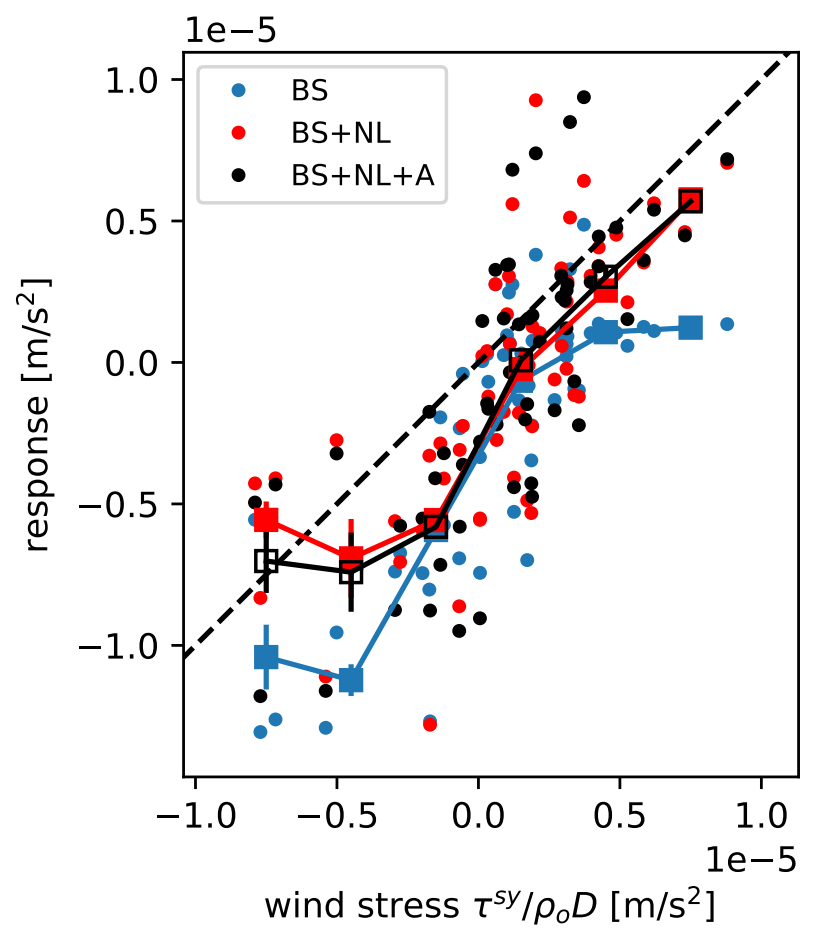

Figure 5: Comparison of wind stress, bottom stress and nonlinear advection terms in the depth-averaged alongshore momentum balance at FRF during June-August. Wind stress term vs. bottom stress (BS) term (blue); wind stress term vs. sum of bottom stress and nonlinear $(\mathrm{BS}+\mathrm{NL}$ ) terms (red); and wind stress term vs. sum of bottom stress, nonlinear and acceleration $(\mathrm{BS}+\mathrm{NL}+\mathrm{A})$ terms (black). Each circle represents a 33-hour average of low-pass filtered data. Squares are bin averages, with vertical lines showing standard errors. 

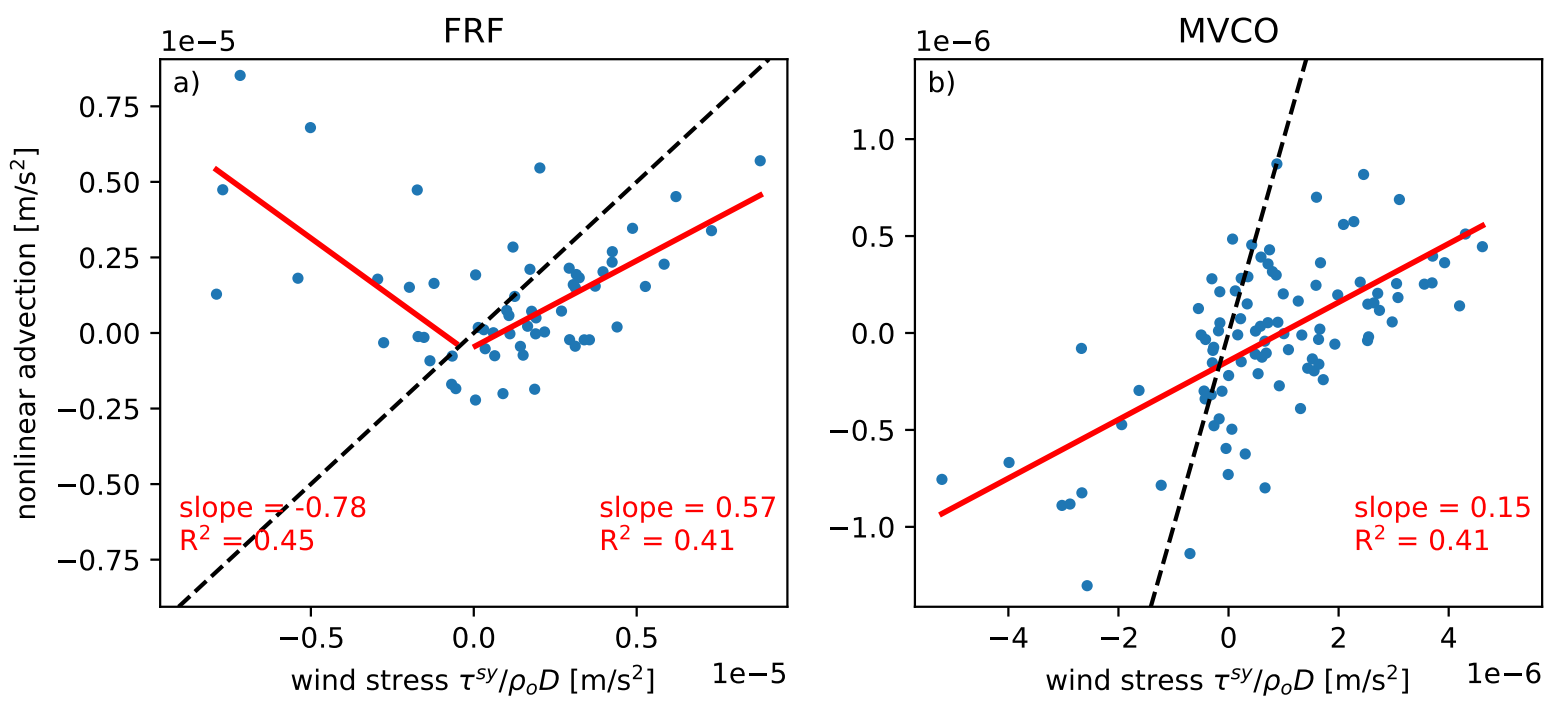

Figure 6: Comparison of wind stress and nonlinear advection terms in the alongshore momentum balance during June-August. a) At FRF over the North Carolina inner shelf. Red lines indicate results of piecewise linear regressions of the 33-hour subsampled values, one regression for positive values of wind stress and another for negative values of wind stress. b) At MVCO over the New England inner shelf. One linear regression is used for both positive and negative values of wind stress. Note difference in scale between panels $a$ and $b$.
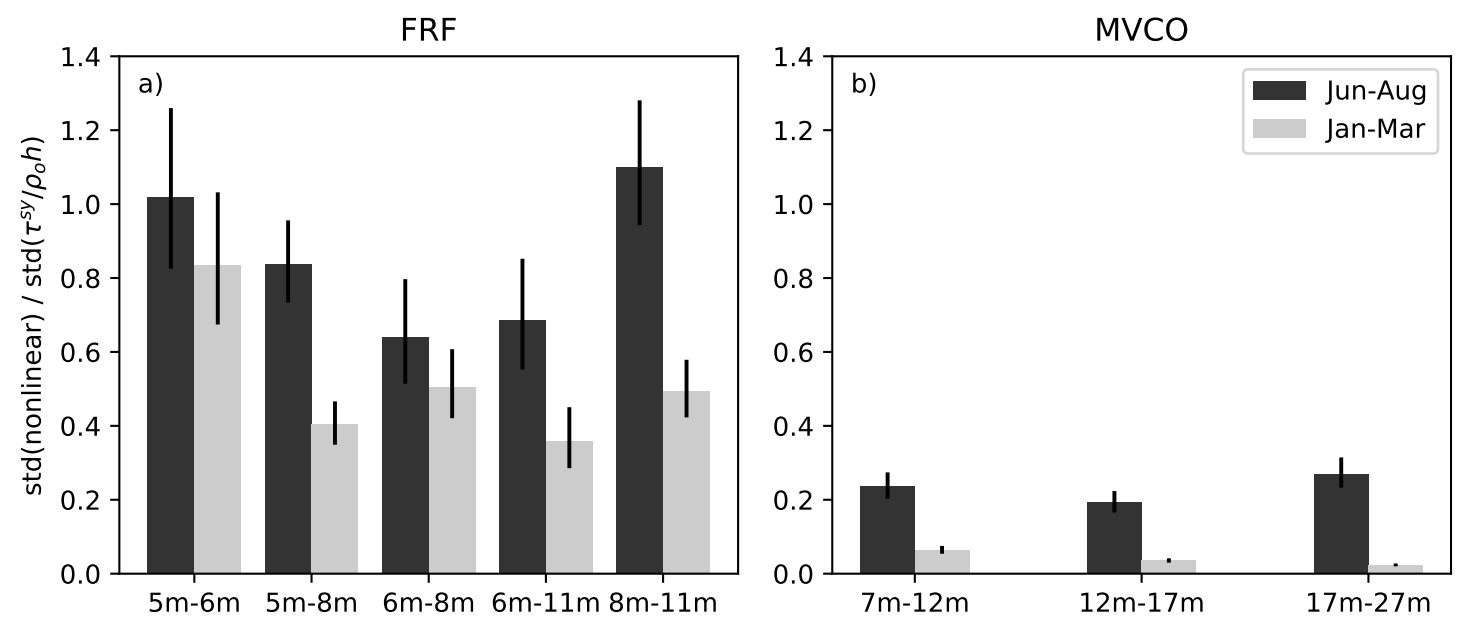

Figure 7: Comparison of variability in the nonlinear and wind stress terms in the alongshore momentum balance. a). Ratio of standard deviations of the nonlinear term and wind stress term at FRF over the North Carolina inner shelf. Black bars show ratios during June-August and gray bars show ratios during January-February. Ratios are shown for five different pairs of sites. Vertical lines indicate $95 \%$ confidence intervals. b) As in panel a, for three pairs of sites at MVCO over the New England inner shelf. 

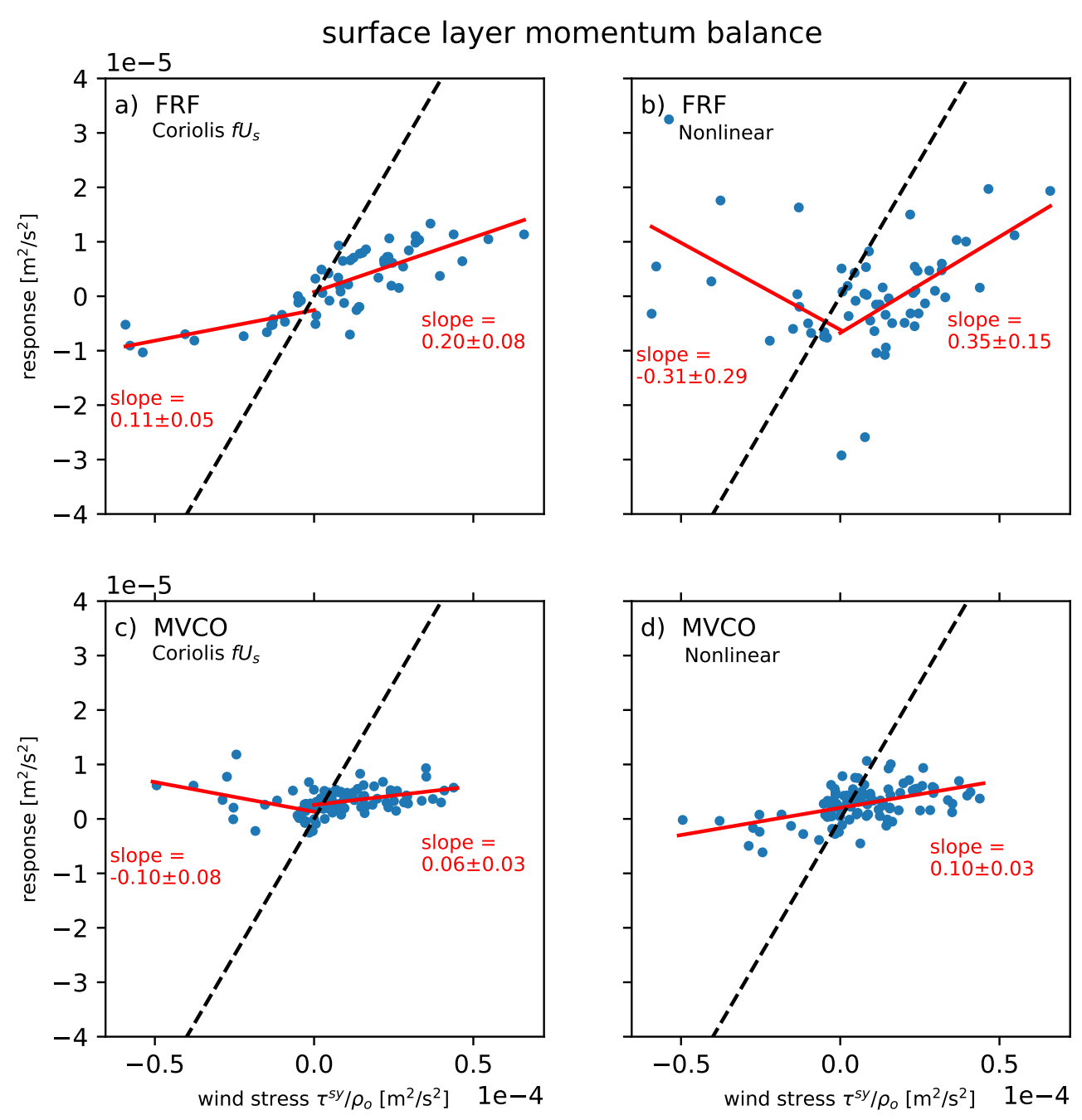

Figure 8: Comparison of wind stress, Coriolis and nonlinear advection terms in the surface layer-integrated alongshore momentum balance at FRF during June-August. a) Wind stress term vs. Coriolis terms at FRF. Each circle indicates a 33-hour average of low-pass filtered data. Lines indicate separate linear regression fits for positive and negative wind stress values. Regression slopes are shown with 95\% confidence intervals. b) As in panel a, for wind stress term vs. nonlinear terms at FRF. c) As in panel a, for wind stress term vs. Coriolis term at MVCO. d) As in panel a, for wind stress term vs. nonlinear terms at MVCO, and with one linear regression fit for all data points. 

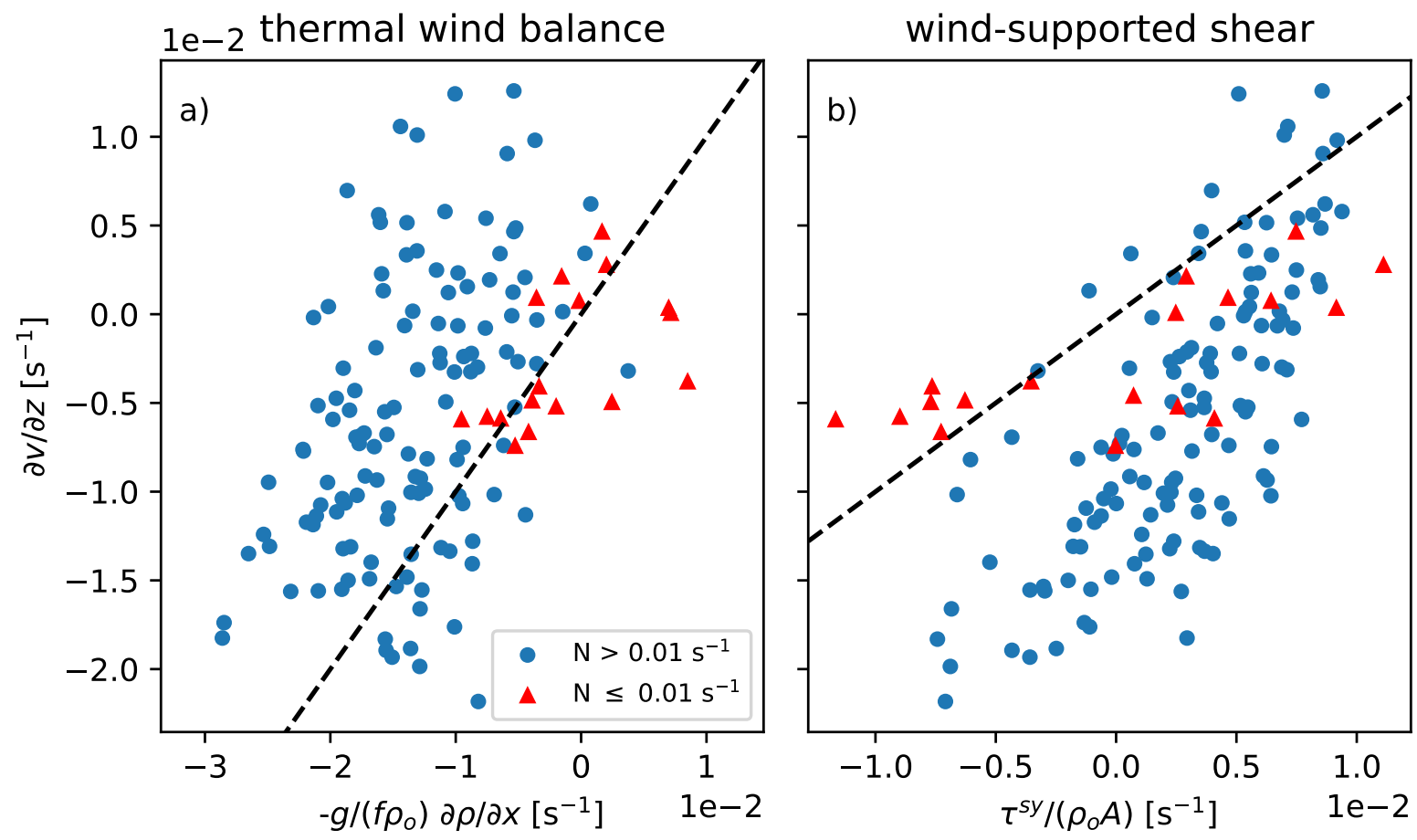

Figure 9: Evaluation of processes governing vertical shear, $\partial v / \partial z$, at MVCO. a) Hypothetical vertical shear associated with thermal wind balance in equation (8). Circles indicate relatively strong stratification, $N>0.01$. Triangles indicate relatively weak stratification, $N \leq 0.01$. Black dashed line indicates 1:1 relationship. b) Hypothetical vertical shear associated with alongshore wind stress $\tau^{s y}$ and eddy viscosity $A=\kappa u_{*} h / 6$ in equation (9). 

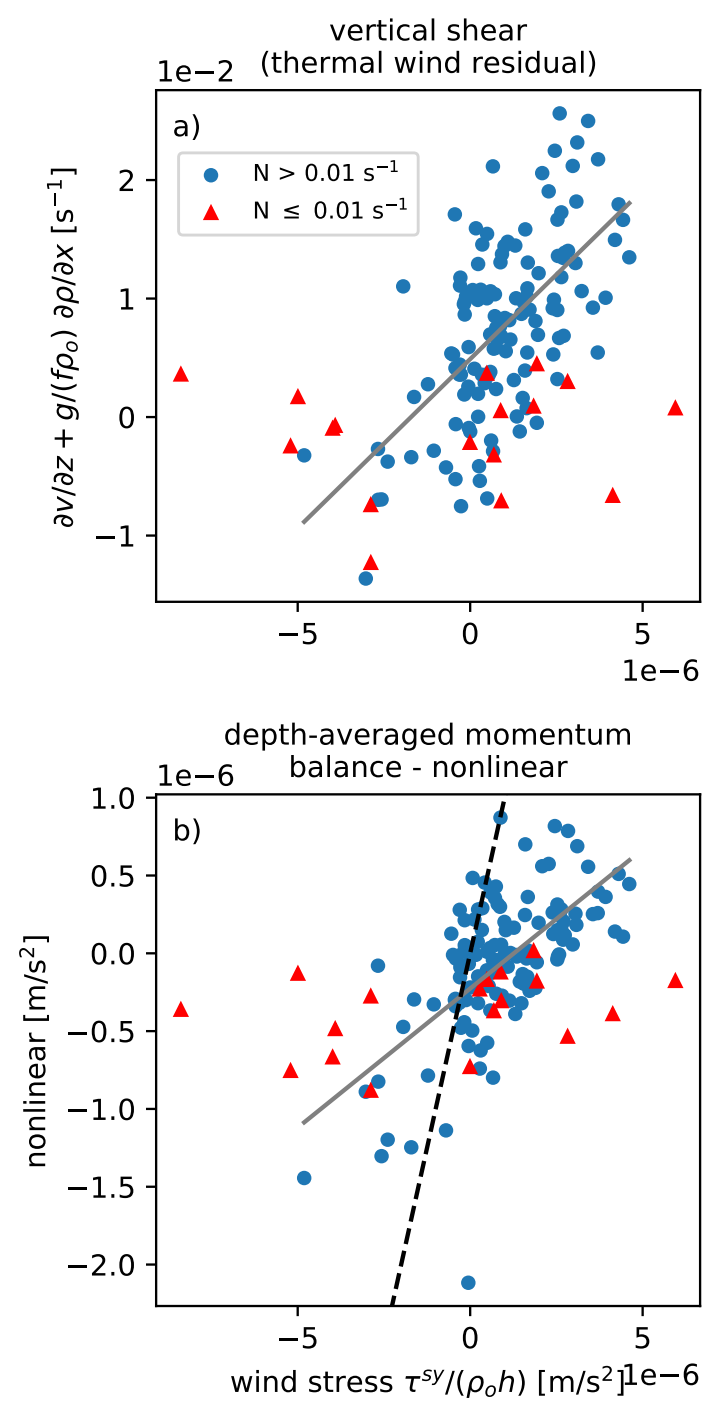

Figure 10: a) Wind stress term $\tau^{s y} /\left(\rho_{o} h\right)$ vs. the thermal wind balance residual $\partial v / \partial z+$ $g /\left(f \rho_{o}\right) \partial \rho / \partial x$ at MVCO. Circles indicate relatively strong stratification, $N>0.01$. Triangles indicate relatively weak stratification, $N \leq 0.01$. b) Wind stress and nonlinear advection terms in the depth-averaged momentum balance at MVCO under different levels of stratification. 

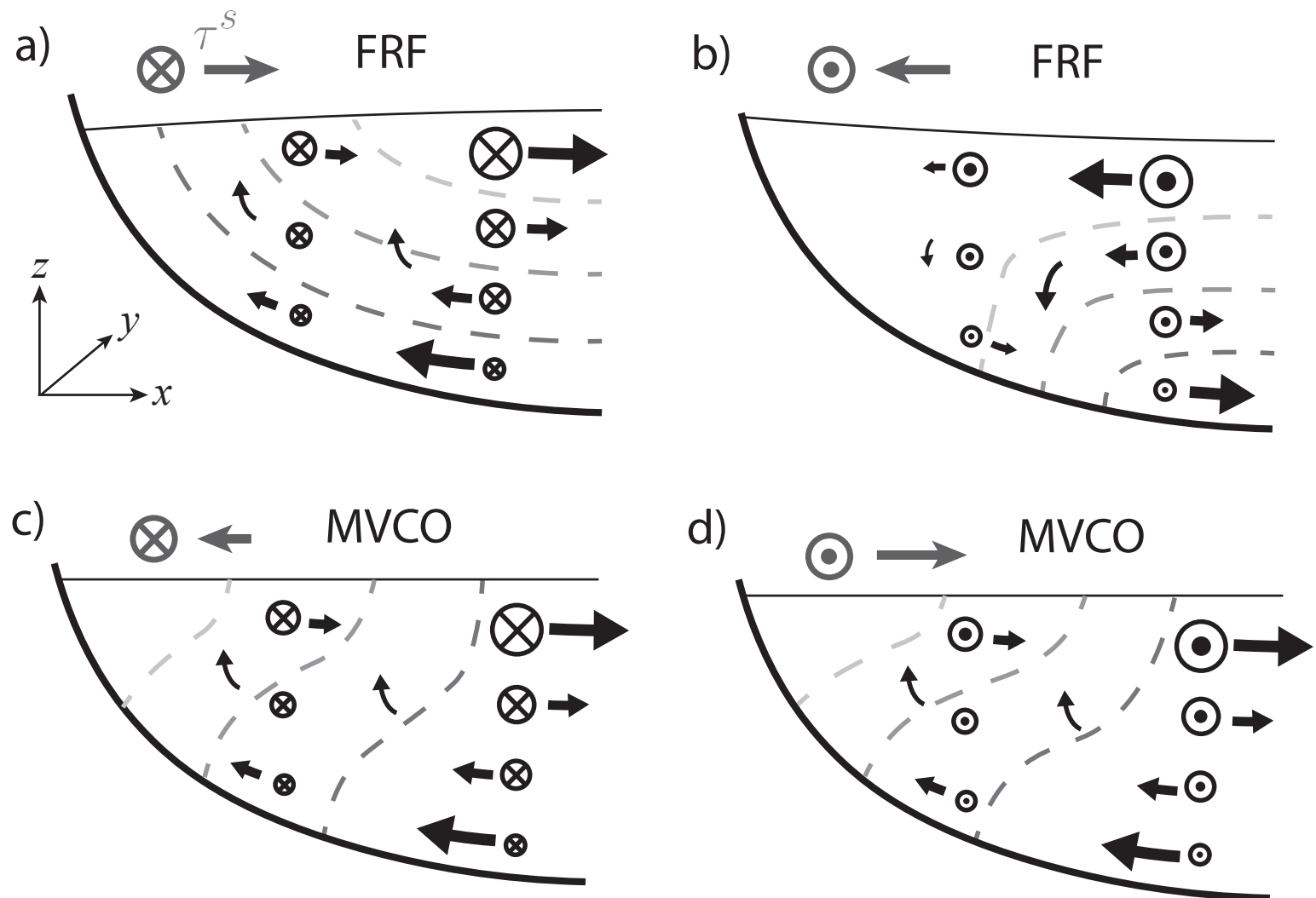

Figure 11: Conceptual models of circulation patterns associated with nonlinear momentum fluxes at different locations and under different forcing conditions. Arrows represent cross-shelf and vertical vector components. Circles represent alongshore vector components ( $\otimes$ indicates wind stress or ocean velocity in the positive $y$ direction). Dashed lines indicate isopycnals, where darker shading is relatively dense. a) FRF, upwelling-favorable and offshore wind stress. b) FRF, downwelling-favorable and onshore wind stress. c) MVCO, upwelling-favorable and onshore wind stress. d) MVCO, downwelling-favorable and offshore wind stress. 


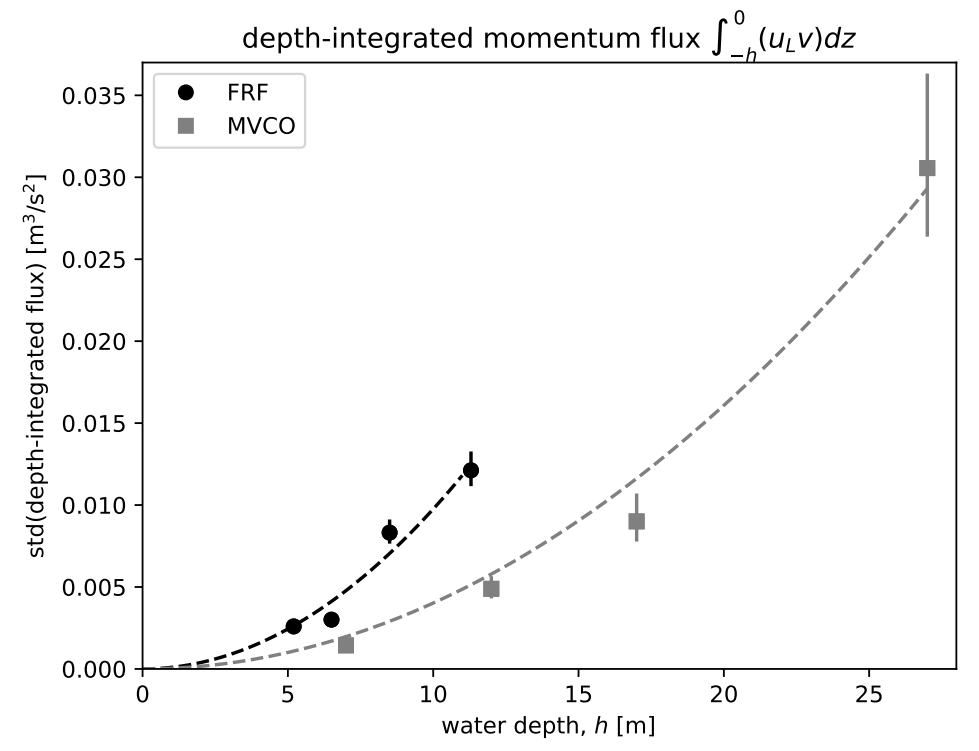

Figure 12: Standard deviations of the depth-integrated nonlinear momentum flux as a function of water depth, for the months of June-August. Black symbols represent estimates from FRF and gray symbols represent estimates from MVCO. Vertical bars indicate $95 \%$ confidence intervals. Dashed lines show hypothetical dependence on $a h^{2}$, where $a$ is a constant coefficient obtained from a least squares fit at each location. 

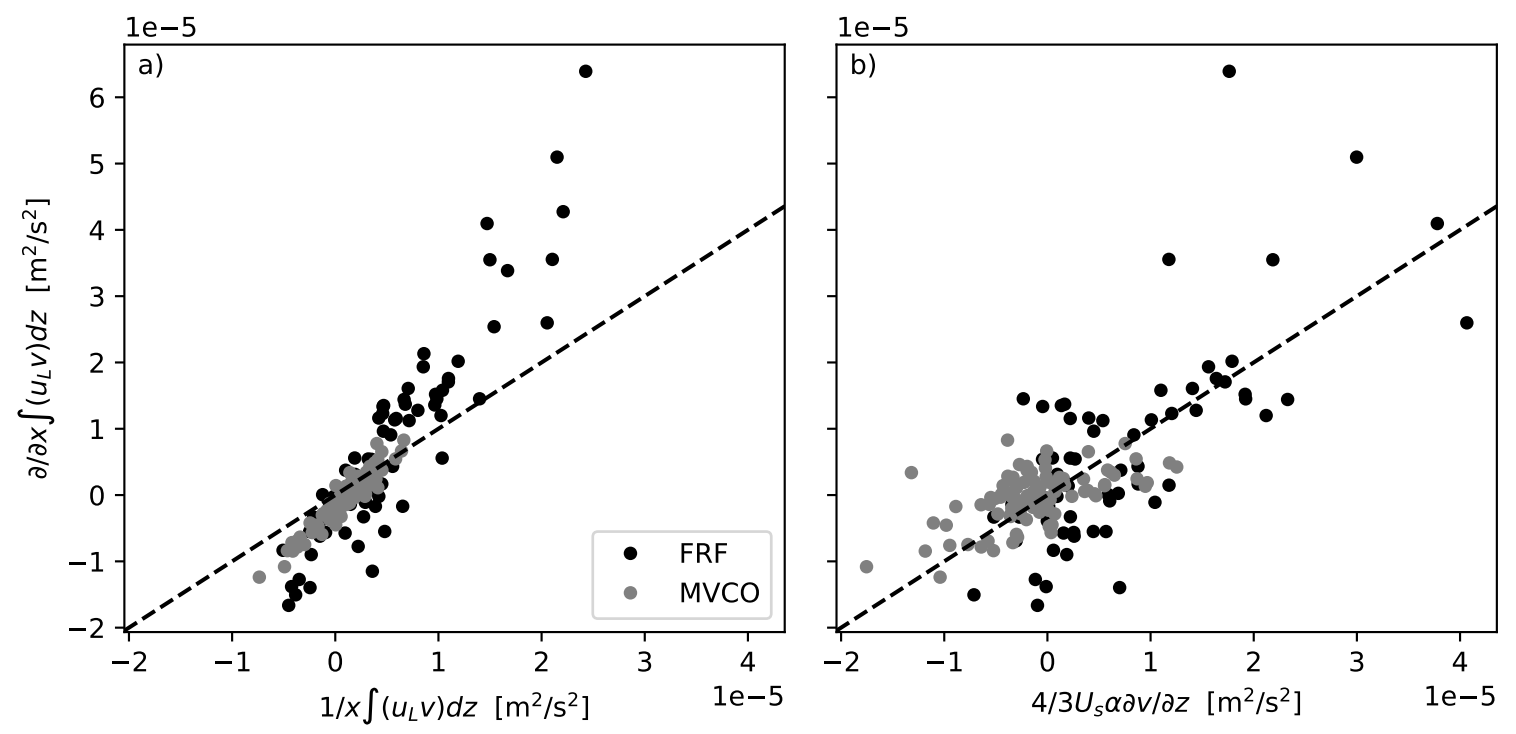

Figure 13: Simplified representations of the nonlinear term in the depth-averaged momentum balance. a) Comparison of the approximation in equation (10) estimated from single deeper mooring ( $x$-axis) vs. full estimate from mooring pairs ( $y$-axis). Black symbols represent estimates from the 6-8m sites at FRF and gray symbols represent estimates from the 7-12m sites at MVCO. Blacked dashed line represents 1:1 agreement. b) Comparison of the scaling in equation (13) estimated from single deeper mooring ( $x$-axis) vs. full estimate from mooring pairs ( $y$-axis). Symbols as in panel a. 